\title{
Spatiotemporal climate and vegetation greenness changes and their nexus for Dhidhessa River Basin, Ethiopia
}

\author{
Gizachew Kabite Wedajo ${ }^{1,2^{*}}$, Misgana K. Muleta ${ }^{3}$, Berhan Gessesse ${ }^{2,4}$ and Sifan A. Koriche ${ }^{5,6}$
}

\begin{abstract}
Background: Understanding spatiotemporal climate and vegetation changes and their nexus is key for designing climate change adaptation strategies at a local scale. However, such a study is lacking in many basins of Ethiopia. The objectives of this study were (i) to analyze temperature, rainfall and vegetation greenness trends and (ii) determine the spatial relationship of climate variables and vegetation greenness, characterized using Normalized Difference in Vegetation Index (NDVI), for the Dhidhessa River Basin (DRB). Quality checked high spatial resolution satellite datasets were used for the study. Mann-Kendall test and Sen's slope method were used for the trend analysis. The spatial relationship between climate change and NDVI was analyzed using geographically weighted regression (GWR) technique.

Results: According to the study, past and future climate trend analysis generally showed wetting and warming for the DRB where the degree of trends varies for the different time and spatial scales. A seasonal shift in rainfall was also observed for the basin. These findings informed that there will be a negative impact on rain-fed agriculture and water availability in the basin. Besides, NDVI trends analysis generally showed greening for most climatic zones for the annual and main rainy season timescales. However, no NDVI trends were observed in all timescales for cool subhumid, tepid humid and warm humid climatic zones. The increasing NDVI trends could be attributed to agroforestry practices but do not necessarily indicate improved forest coverage for the basin. The change in NDVI was positively correlated to rainfall $\left(r^{2}=0.62\right)$ and negatively correlated to the minimum $\left(r^{2}=0.58\right)$ and maximum $\left(r^{2}=0.45\right)$ temperature. The study revealed a strong interaction between the climate variables and vegetation greenness for the basin that further influences the biophysical processes of the land surface like the hydrologic responses of a basin.

Conclusion: The study concluded that the trend in climate and vegetation greenness varies spatiotemporally for the DRB. Besides, the climate change and its strong relationship with vegetation greenness observed in this study will further affect the biophysical and environmental processes in the study area; mostly negatively on agricultural and water resource sectors. Thus, this study provides helpful information to device climate change adaptation strategies at a local scale.
\end{abstract}

Keywords: Spatiotemporal changes, Vegetation greenness, Mann-Kendall test, Sen's slope method, Dhidhessa River Basin

\section{Introduction}

Rainfall and temperature are key climate variables that vary in time and space. Their variation from the longterm mean is used as a proxy for climate change studies. Most climate change studies, therefore, focus on

\footnotetext{
*Correspondence: Kabiteg@gmail.com

${ }^{1}$ Department of Earth Sciences, Wollega University, P.O.Box 395, Nekemte, Ethiopia

Full list of author information is available at the end of the article
}

temperature and rainfall trend analysis. Studies indicated increasing temperature in Ethiopia (Conway et al. 2004; Conway and Schipper 2011; Mengistu et al. 2014; Addisu et al. 2015) and in most parts of the world (IPCC 2007, 2013). However, rainfall trend studies show inconsistent results (Conway 2000; Seleshi and Zanke 2004; Jury and Funk 2012). Likewise, increasing temperature (Mengistu et al. 2014; Addisu et al. 2015) but inconsistent rainfall trends (Conway 2000; Elshamy et al. 2009; Tesemma 
et al. 2010; Gebremicael et al. 2013; Mellander et al. 2013) are reported in the upper Blue Nile basin. The discrepancies could be attributed to the difference in the spatial and temporal scales of the studies and the local factors like topography and geographic locations (Mengistu et al. 2014).

For example, annual rainfall in Ethiopia is spatiotemporally variable with a $20 \%$ to $80 \%$ coefficient of variation (Addisu et al. 2015). The southwestern highland region of the country receives $>2000 \mathrm{~mm}$ mean annual rainfall mainly from June to September while the eastern and southeastern lowland regions receive $<250 \mathrm{~mm}$ from March to May (Segele and Lamb 2005; Abtew et al. 2009; Addisu et al. 2015). In the case of the upper Blue Nile basin, annual rainfall declines from $>2000 \mathrm{~mm}$ in the southwestern to $<1000 \mathrm{~mm}$ in the northeastern part of the basin (Conway 2000), which implies the existence of climatic zones even within a basin. Furthermore, about $80 \%$ of the annual rainfall for the basin occurs during the main rainy season from June to September (Conway 2005). As such, reliable information on climate trends at a local scale is important for understanding the local and regional climate impacts.

In line with the past climate trends, model projection results show increasing temperature (Elshamy et al. 2009; Beyene et al. 2010; IPCC 2013) and inconsistent rainfall trends (Beyene et al. 2010; Setegn et al. 2011; IPCC 2013; Mekonnen and Disse 2018) for Ethiopia in general and for the upper Blue Nile basin in particular. The discrepancies among rainfall projection results are attributed to uncertainties of the models and differences in local factors such as topography and vegetation cover. For an instant, the new state-of-the-art climate models, coupled model intercomparison project phase 5 (CMIP5) GCMs, predict climate variables better than the previous Coupled Model Intercomparison Project (CMIP3) GCMs (Knutti and Sedlacek 2012). This is attributed to the use of a new set of radiative forcing scenarios (i.e., representative concentration pathway, RCP), the inclusion of land cover change impacts and incorporation of important biogeochemical processes in the CMIP5 GCMs (IPCC 2013). These changes have had a positive impact over the upper Blue Nile basin, where temperature and rainfall over the region were more accurately predicted by canESM2 from CMIP5 than HadCM3 from CMIP3 (Mekonnen and Disse 2018). This does not mean, however, that the CMIP5 GCMs are perfect in predicting climate variables for the basin. There exists variation in the performance among the CMIP5 GCMs models (Bhattacharjee and Zaitchik 2015). A model that captures regional rainfall may not capture temperature variability, or a model that performs well for one region may not be reliable in another region.
Consequently, GCMs should be carefully selected before projecting climate variables and because the spatial resolution of GCMs outputs is generally too coarse for local and regional climate studies, their simulation results should be downscaled. Downscaling the GCMs model outputs could increase the accuracy of analyzing the impacts of climate change on hydrological responses at a local scale.

Besides, as both climate and land cover changes affect hydrological responses of a basin, their interaction should be known. For an instant, Mekonnen et al. (2018) reported declining river flow of the upper Blue Nile attributed to the combined effects of land cover and climate changes. The land cover change affects river flow positively or negatively depending on the type and intensity of the changes. For example, increasing wet season streamflow was reported in the upper Blue Nile due to deforestation and increasing rainfall (Mekonnen et al. 2018) whereas afforestation and warming conditions may reduce streamflow by increasing infiltration and transpiration loss. These imply that the land cover change either exacerbate or improve the effects of climate change on river flow. Also, land cover and climate changes are strongly linked (Dale 1997). For example, deforestation exacerbates climate change while dry and warm climatic condition leads to reduced vegetation growth. Therefore, understanding the nexus between climate variables (e.g., temperature and rainfall) and vegetation greenness is important for managing natural resources, designing climate change adaptation strategies and forecasting extreme weather events such as drought and flooding (Conway 2005; Samy et al. 2015).

A common approach used to examine the nexus between climate and vegetation greenness (condition) is regressing climate variables (e.g., temperature and rainfall) against the Normalized Difference Vegetation Index (NDVI), a remote sensing-based index commonly used in measuring vegetation greenness (Jiang et al. 2006). However, the relationships between NDVI and climate variables are affected by the auto-correlated biophysical factors such as vegetation, soil and land use type (Ji and Peters 2004). The non-stationarity, non-linearity and scale dependency of NDVI-climate variables relationship can be effectively modeled using geographically weighted regression (GWR) (Foody 2003, 2004; Propastin et al. 2008). The GWR calculates spatially varying regression model parameters (Fotheringham et al. 2002) and reduces errors that emanate from the spatially autocorrelations between the variables (Usman et al. 2013). Studies have reported the superiority of GWR over ordinary least squared (OLS) in its descriptive and predictive power (Propastin et al. 2008; Zhao et al. 2010; Usman et al. 2013; Tian et al. 2015). 
Therefore, studying the spatiotemporal changes of climate and vegetation greenness, and their interaction at a basin-scale is important for understanding climate change impacts locally. The Dhidhessa River basin is one of the upper Blue Nile sub-basins that receive higher average annual rainfall $(>1600 \mathrm{~mm})$, contribute more than $25 \%$ annual flow to the Blue Nile basin, covered with dense vegetation and with less steep topography compared to the northeastern sub-basins (Conway 2000). These imply studying climate trends at a sub-basin scales could improve the accuracy of predicting local and regional climate change impacts on water resource availability (Kim and Kaluarachchi 2009; Viviroli et al. 2011), agriculture (Deressa and Hassan 2009; Schlenker and Lobell 2010; Philip et al. 2014; Regan et al. 2018), human health (McMichael et al. 2006) and biodiversity (Chapungu and Nhamo 2016; Perović et al. 2019).

However, the extent of climate change and its impacts are not well known for the DRB as the basin is with scarce data and generally less studied. Moreover, like for the other basins in Ethiopia, up-to-date and reliable climate trends and their relation with vegetation greenness is lacking in the DRB. A comprehensive study encompassing climate and NDVI trend analysis and their relationship at a local scale is beneficial for effective land resource management and implementing climate change adaptation strategies. Such a study is particularly important for the DRB where rain-fed agriculture is the major occupation and water resource development projects in the basin are sensitivity to climate change (Schlenker and Lobell 2010; Mekonnen et al. 2018).

Consequently, this study analyzed (i) past and future temperature and rainfall trends, (ii) past NDVI trend and (iii) determined spatial relationship of climate variables with the NDVI for the DRB. To the best of our knowledge, such a comprehensive study was not done previously. The study will provide baseline information for designing climate adaptation strategies that minimize the effects of climate change on water resources and agriculture, specific to this region. Such information is essential to examine water resources availability and sustain agricultural production in the DRB.

\section{Methods and materials}

\section{Description of the study area}

The DRB is located in the southwestern part of the upper Blue Nile basin (Fig. 1). Dhidhessa River is one of the largest tributaries of the Blue Nile River and is regarded as the most important tributary in terms of its flow contribution (Yohannes 2008). Located between $7^{\circ} 42^{\prime} 43^{\prime \prime}$ to $10^{\circ} 2^{\prime} 55^{\prime \prime}$ latitudes and $35^{\circ} 31^{\prime} 23^{\prime \prime}$ to $37^{\circ} 7^{\prime} 60^{\prime \prime}$ longitudes, the river basin exhibits highly variable topography that ranges from 619 to $3213 \mathrm{~m}$ above mean sea level (a.m.s.l).
The river starts from Sigmo mountain ranges (i.e., Mt. Vennio and Mt. Wache) and travels $494 \mathrm{~km}$ before it joins the upper Blue Nile River around Wanbara and Yaso districts. The confluence of the Dhidhessa River and the upper Blue Nile River was used as the outlet of this study basin resulting in a total drainage area of $28,175 \mathrm{~km}^{2}$. The River basin has many perennial tributaries (Fig. 1).

According to the Ethiopian agro-ecological zone (AEZ) classification (MoA 1998), the DRB is classified into seven climatic zones (Fig. 1). AEZ is a homogeneous unit in terms of its climate, terrain, soil, vegetation and fauna. Descriptions of the AEZ are presented in Appendix Table 10. The dominant AEZ includes tepid sub-humid (42\%), warm sub-humid (32\%) and warm moist (23\%) while the remaining climatic zones cover only $3 \%$ of the basin.

Temperature and rainfall in the DRB exhibit spatial and seasonal variability. The mean daily maximum and minimum air temperature of the basin is $26.5{ }^{\circ} \mathrm{C}$ and $13{ }^{\circ} \mathrm{C}$, respectively. Besides, the mean annual rainfall of the basin is $1675 \mathrm{~mm}$ where about $70 \%$ of the rainfall occurs from June to September. The lowlands, primarily located in the northwest part of the river basin, are relatively warmer and receive less rainfall whereas the highlands are cooler and receive higher rainfall totals.

\section{Data sources and description}

Ground-based measured climate data are either scarce or low quality in Ethiopia, particularly in the DRB (Conway 2000; Tena et al. 2016). As a result of this, we used quality-controlled satellite-derived datasets for this study. The 4-km gridded monthly minimum and maximum temperature dataset, which was constructed by the Enhanced National Climate Time-series Service (ENACTS) initiative was obtained from the National Meteorological Agency (NMA) of Ethiopia for the 1983 to 2015 period. The ENACTS derived temperature dataset was produced by merging the Moderate Resolution Imaging Spectroradiometer (MODIS) satellite land surface temperature (LST) with over 300 temperature stations data over Ethiopia (Tufa et al. 2018). Similarly, Climate Hazards Group InfraRed Precipitations with Stations (CHIRPS) version 2 derived rainfall product (http://dx.doi.org/10.15780/ G2RP4Q) was used for the rainfall trend analysis.

Ground-based climate datasets were used to evaluate the accuracy of the ENACTS and CHIRPS-v2 datasets and to validate the climate models used in this study. As such, ground-based daily minimum and maximum temperature and rainfall measurements for eight stations within the river basin and additional six nearby stations were obtained from NMA of Ethiopia from 1983 to 2015 (Fig. 1). The missing ground-based climate data were filled using daily long-term averages. The study period from 1983 to 

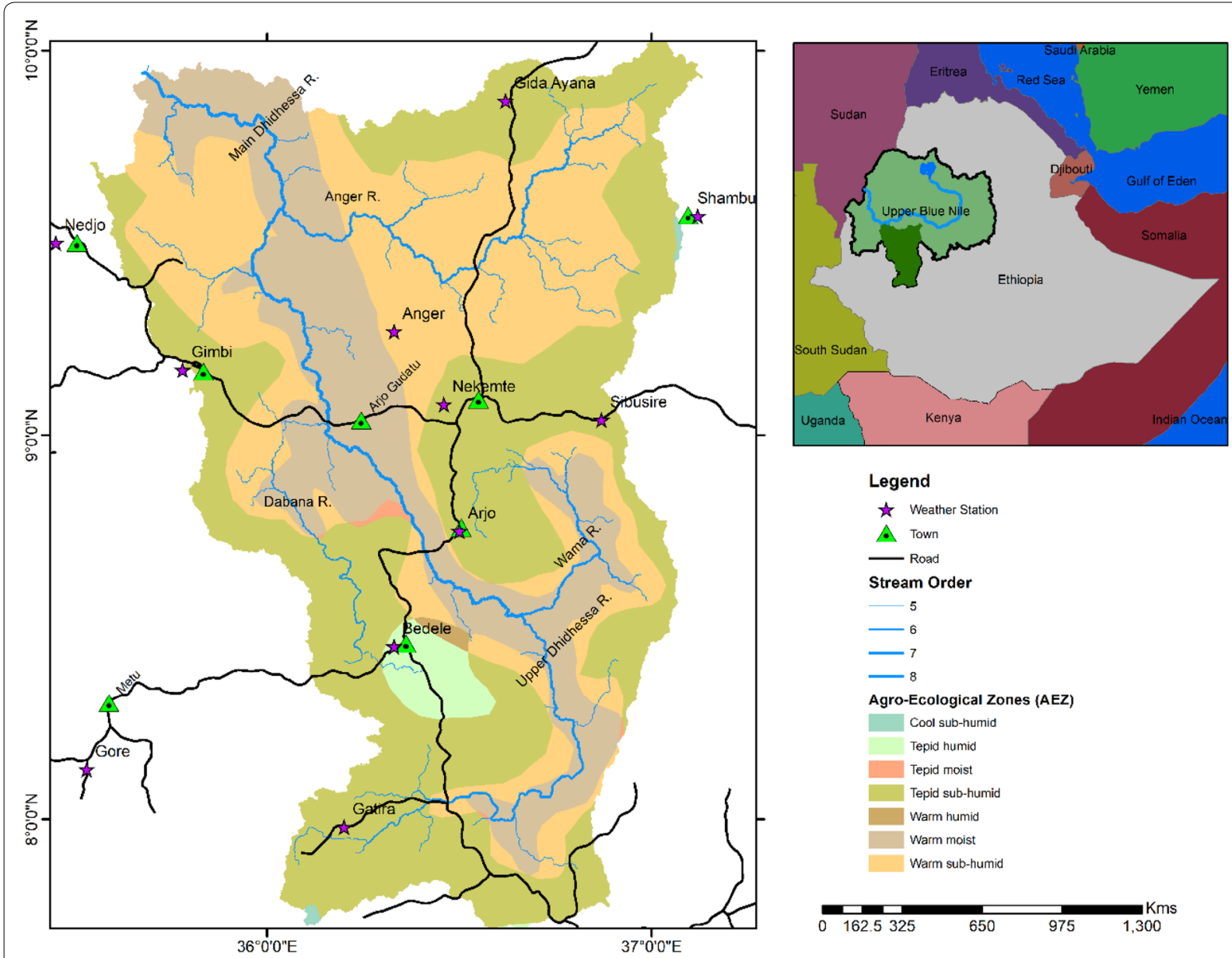

Fig. 1 Location map of the Dhidhessa River basin with ground stations

2015 was chosen based on the availability of the ENACTS and CHIRPS datasets. Moreover, ENACTS and CHIRPS are the only long-term records of temperature and rainfall dataset available at a high spatial resolution for the study area. Therefore, these datasets were preferred in this study for climate trend analysis owing to its good agreement with ground-based measured data and their long-term records.

On the other hand, the normalized difference vegetation index-3rd generation (NDVI3g) data developed by the global inventory, monitoring and modelling studies (GIMMS) program was used for this study (https:// ecocast.arc.nasa.gov/data/pub/gimms3g.v1) to analyze vegetation trends for the DRB. The data were captured using the United States National Oceanic and Atmospheric Agency's (NOAA) advanced very high-resolution radiometer (AVHRR2/3) sensors. The GIMMS NDVI3g dataset spans from July 1981 to December 2015 and is available at $8-\mathrm{km}$ spatial resolution and 15-day interval. It is the longest global dataset available on vegetation conditions and is suitable for trend analysis and climate change impact studies (Tian et al. 2015; He et al. 2017).
For comparison purposes, the NDVI3g dataset from 1983 to 2015 was used for the trend and regression analysis. The spatial relationships between vegetation greenness and the climate variables were examined by regressing the long-term NDVI and climate variables (i.e., temperature and rainfall) for the 1983 to 2015 period.

Moreover, the dynamically downscaled GCMs climate variables generated by the coordinated regional climate downscaling experiment for Africa (CORDEX-Africa) initiative were also used for future climate trend analysis.

\section{Methodology}

Rainfall and temperature are the two major climatic variables that control the atmosphere and the hydrological processes at the global, regional and basin scales (Tanzeeba and Gan 2012). Minimum and maximum temperature from ENACTS and rainfall from CHIRPS-v2 were used for the historic climate trend analysis. The reliability of the datasets was examined using the ground station datasets as previously described. Fourteen gauging station datasets were used to evaluate the reliability 
of ENACTS and CHIRPS-v2 datasets using Pearson linear correlation techniques. Likewise, the reliability of the dynamically downscaled global climate model (GCMRCM) outputs (e.g., CORDEX-Africa) were also examined using the ground station datasets. Statistical indices such as percent bias, Root Mean Square Error (RMSE) and Pearson correlation coefficient (corr.) were used to evaluate the GCM-RCM performance.

The quality checked ENACTS derived temperature, CHIRPS-v2 derived rainfall, GCM-RCM derived projected climate datasets and GIMMS NDVI3g dataset was used for the climate and vegetation greenness trend analysis for the DRB. The datasets were aggregated at monthly, annual and seasonal timescales. Three seasons namely dry season (October to February), short rainy season (March to May) and a main rainy season (June to September) were considered as suggested by Rosell (2011). Spatially, the datasets were aggregated based on AEZ. As such, the trend analysis was performed for each AEZ at annual, seasonal and monthly timescales for the 1983 to 2015 period. The Mann-Kendall test and Sen's slope method were used for the trend analysis. The relationships between climate variables and NDVI were analyzed using the GWR approach. The descriptions of these methods are in the next few sections.

\section{Climate projection}

The dynamically downscaled CMIP5 GCMs such as MPIESM-LR, HadGEM2-ES, MIROC5, GFDL-ESM2M and EC-EARTH with RCP4.5 and 8.5 emission scenario were used in this study. The CMIP5 GCMs were downscaled using RCA4, a regional climate models (RCMs) recommended for African basins. The projection and downscaling of the datasets were done by CORDEX-Africa initiatives at Rossy Center. The datasets are available at 50-km spatial resolution from WCRP (https://esgf-node. llnl.gov) and were used for future temperature and rainfall trend analysis for the 2050 periods.

\section{Mann-Kendall test}

Mann-Kendall test is a non-parametric method widely used for monotonic trend analysis. It is less sensitive to outliers and is a robust technique to detect trends in climatic variables (Keredin et al. 2013). The method is appropriate for data that exhibit constant variance over time. It tests the null hypothesis of no trend against the alternative hypothesis where there is an increasing or decreasing monotonic trend. The statistics of the test is given as follows (Burn 1994):

$$
Z= \begin{cases}(S-1) / \sqrt{\operatorname{Var}(S)} & S>0 \\ 0 & S=0 \\ (S+1) / \sqrt{\operatorname{Var}(S)} & S<0\end{cases}
$$

where $\mathrm{Z}$ is the normalized test statistic

$$
S=\sum_{i=1}^{n-1} \sum_{k=i+1}^{n} \operatorname{sgn}\left(x_{k}-x_{i}\right)
$$

$x_{k}$ and $x_{i}$ are the annual values in years $\mathrm{k}$ and $\mathrm{i}$, respectively; $\mathrm{n}$ is the length of a dataset,

$$
\operatorname{sgn}\left(x_{k}-x_{i}\right)= \begin{cases}1 & \text { if } x_{k}-x_{i}>0 \\ 0 & \text { if } x_{k}-x_{i}=0 \\ -1 & \text { if } x_{k}-x_{i}<0\end{cases}
$$

$\operatorname{Var}(S)$ represent the variance in the data and is determined using Eq. (4) based on ties (i.e., equal values).

$$
\operatorname{VAR}(S)=\frac{1}{18}\left[n(n-1)(2 n+5)-\sum_{p=1}^{q} t_{p}\left(t_{p}-1\right)\left(2 t_{p}+5\right)\right]
$$

where $q$ is the number of tied groups and $t_{p}$ is the number of data values in the $p$ th group.

Positive $Z$ value indicates increasing while a negative value represents decreasing. The hypothesis (i.e., no trend) is rejected if the absolute value of $\mathrm{Z}$ is greater than $Z_{1-\alpha / 2}$ (i.e., $\left.\left|Z_{0.05}\right|>1.96\right)$ where $\alpha=$ is the significant level $(0.05$ is used for this study).

\section{Sen's slope method}

The true slope of a linear trend (i.e., change per year) was estimated from the Sen's nonparametric method as follows (Sen 1968):

$$
f(t)=Q t+B
$$

where $Q$ is slope of the trend line and $B$ is a constant.

The slope, $Q$, is calculated as,

$$
Q_{i}=\frac{x_{i}-x_{k}}{i-k}, \quad \text { where } i>k .
$$

If $n$ is the number of data values (i.e., $x_{i}$ ) in the time series, then the number of slope estimates that can be calculated using Eq. 6 will be $N=n(n-1) / 2$; where $\mathrm{N}$ is the number of slopes. Sen's slope is the median of these $N$ slope values. The $Q_{i}$ values are ranked from the smallest to the largest and the slope was calculated as:

$$
\begin{aligned}
& Q=Q_{\left[\frac{N+1}{2}\right], \quad \text { if } N \text { is odd or }} \\
& Q=\frac{1}{2}\left(Q_{\left[\frac{N}{2}\right]}+Q_{\left[\frac{N+2}{2}\right]}\right), \quad \text { if } N \text { is even. }
\end{aligned}
$$

\section{Geographically weighted regression}

As previously described, trends in vegetation greenness of the DRB was analyzed using the NDVI3g data derived from NOAA/AVHRR for the 1983 to 2015 period. The 
maximum value composite (MVC) method, which reduces the impacts of atmospheric effect, was used to derive monthly NDVI values from the 15-day interval values. Mann-Kendell test and Sen's slope method were used for analyzing NDVI trends at annual, seasonal and monthly timescales. Spatial relationships between NDVI and climate (i.e., temperature and rainfall) were examined for the DRB using the GWR techniques. GWR is a local regression method that calculates the spatial relationship between NDVI and temperature or rainfall at multiple locations builds a local regression equation for each feature in the dataset (Foody 2003). The GWR model can be described as:

$$
y_{\left(u_{i}, v_{i}\right)}=\beta_{0}\left(u_{i}, v_{i}\right)+\beta\left(u_{i}, v_{i}\right) x_{\left(u_{i}, v_{i}\right)}+\varepsilon_{\left(u_{i}, v_{i}\right)}
$$

where $y_{\left(u_{i}, v_{i}\right)}$ is the dependent variable (in this case NDVI) at point $(i) ; x_{\left(u_{i}, v_{i}\right)}$ is the independent variable (in this case temperature or rainfall) at point $(i) ;\left(u_{i}, v_{i}\right)$ is geographic coordinates of point $(i), \beta_{0}\left(u_{i}, v_{i}\right)$ is the spatially varying intercept and $\beta\left(u_{i}, v_{i}\right)$ is spatially varying weight coefficient; $\varepsilon_{\left(u_{i}, v_{i}\right)}$ is spatially varying random error at point $(i)$.

The fixed Gaussian kernel function was used for this study to compute weighted coefficients, which was preferred as the data is regularly distributed in space. Bandwidth for the function was determined using the Akaike Information Criterion (AIC). As such, GWR uses location-specific weight coefficients to account for the spatial non-stationarity, which makes the method robust compared to OLS that uniformly apply coefficients across the study area (Foody 2003; Propastin et al. 2008; Zhao et al. 2010; Usman et al. 2013; Tian et al. 2015; Zhao et al. 2015).

\section{Results}

Performance evaluation of climate datasets

The Pearson linear correlation analysis showed that the monthly minimum and maximum temperature values from ENACTS products were strongly correlated $\left(r^{2}=0.71\right.$ and 0.89 , respectively $)$ to the temperature values obtained from the ground stations. Likewise, monthly CHIRPS-v2 rainfall showed a strong correlation $\left(r^{2}=0.92\right)$ with that of the ground station rainfall data. The results suggest that the ENACTS and CHIRPS-v2 datasets are viable for climate trend analysis. Likewise, the performance evaluation results of the GCM-RCM from CORDEX-Africa are described in Table 1.

The result showed that all the models used for this study underestimated rainfall and overestimated temperature except the EC-EARTH model. The EC-EARTH and MIROC5 models performed well in simulating rainfall with the lowest bias and RMSE while EC-EARTH and GFDL-EMS2M models performed better in simulating temperature. However, the HadGEM2 model poorly performed, with the highest bias and RMSE, in simulating rainfall and temperature (Table 1). The correlation coefficients were generally low for all models implying the models do not match well with the observed dataset at annual timescale, which indicates the GCM-RCM used in this study do not capture annual climate variability. In contrast, the ensemble mean model performed well compared to most of the individual models. Overall, the EC-EARTH, GFDEL-EMS2M, MIROC5 and the ensemble mean models captured the patterns of the observed climate data for the DRB. Therefore, the future climate trend analysis was performed using the simulation outputs of those models.

Table 1 Performance of the GCM-RCM models for DRB (2006-2015)

\begin{tabular}{|c|c|c|c|c|c|c|c|}
\hline & Observed & EC-EARTH & GFDL-EMS2M & HadGEM2 & MIROC5 & MPI-ESM & Ensemble mean \\
\hline Mean annual rainfall (mm) & 1691 & 1723.74 & 1370.06 & 1275.18 & 1465.38 & 1379.93 & 1442.86 \\
\hline Mean annual $\mathrm{T}_{\max }\left({ }^{\circ} \mathrm{C}\right)$ & 25 & 24.20 & 25.47 & 26.39 & 26.07 & 25.81 & 25.59 \\
\hline Mean annual $\mathrm{T}_{\min }\left({ }^{\circ} \mathrm{C}\right)$ & 13 & 13.23 & 14.25 & 14.85 & 14.97 & 14.24 & 14.31 \\
\hline \multicolumn{8}{|l|}{ Rainfall } \\
\hline Bias (\%) & - & 1.93 & -18.98 & -24.59 & -13.34 & -18.40 & -14.68 \\
\hline RMSE (mm/year) & - & 169.93 & 328.72 & 440.74 & 248.74 & 343.82 & 262.29 \\
\hline Corr. & - & -0.28 & 0.59 & -0.16 & 0.06 & -0.63 & -0.37 \\
\hline \multicolumn{8}{|l|}{ Maximum temperature } \\
\hline Bias (\%) & - & -1.47 & 3.70 & 7.47 & 6.14 & 5.08 & 4.18 \\
\hline RMSE (mm/year) & - & 0.53 & 1.01 & 1.87 & 1.63 & 1.3 & 1.07 \\
\hline Corr. & - & -0.16 & 0.15 & -0.17 & 0.18 & -0.10 & 0.05 \\
\hline \multicolumn{8}{|l|}{ Minimum temperature } \\
\hline Bias (\%) & - & 3.43 & 11.40 & 16.11 & 17.00 & 11.36 & 11.86 \\
\hline RMSE (mm/year) & - & 0.57 & 1.50 & 2.10 & 2.20 & 1.50 & 1.53 \\
\hline Corr. & - & 0.12 & 0.06 & -0.08 & 0.56 & 0.14 & 0.45 \\
\hline
\end{tabular}




\section{Historic rainfall trend analysis}

Figure 2 shows rainfall trend results for the annual and seasonal timescales. While the annual rainfall generally increased for all climatic zones, statistically significant trends at 0.05 level were observed for only warm subhumid and warm moist climate zones. The slope of the trend was $4.55 \mathrm{~mm} /$ year for the warm sub-humid while it was $3.36 \mathrm{~mm} /$ year for the warm moist. However, no trends were observed at all seasons for all climatic zones. Besides, compared to the seasonal timescale, the magnitudes of the changes were highest during the annual timescale for all climatic zones except for the cool subhumid zone (Fig. 2). However, the slope of the dry season rainfall trend was lowest for all climatic zones except for the cool sub-humid zone. For the cool sub-humid zone, a higher rainfall increase during the short rainy season and declining rainfall during the main rainy season were observed. On the other hand, for the warm sub-humid and tepid moist climatic zones, a higher rainfall increases during the short rainy season while a higher rainfall increase during the main rainy season was observed for the tepid humid zones.

Monthly rainfall trend results are showed in Table 2. The result showed increasing rainfall trends in all climatic zones for May except for the tepid humid and warm humid. Besides, significant increasing rainfall trends were observed during June and September for warm humid and tepid moist zones, respectively.

Nevertheless, rainfall from December to March showed decreasing with no trend for all climatic zones except for the warm moist zone. The highest increasing rainfall trend was observed for the cool sub-humid zone for May (i.e., $3.66 \mathrm{~mm} /$ year). The study generally revealed intermonthly and spatially variable rainfall trends (Table 2).

Overall, rainfall trends were observed only for the annual timescale but no trends were observed for the
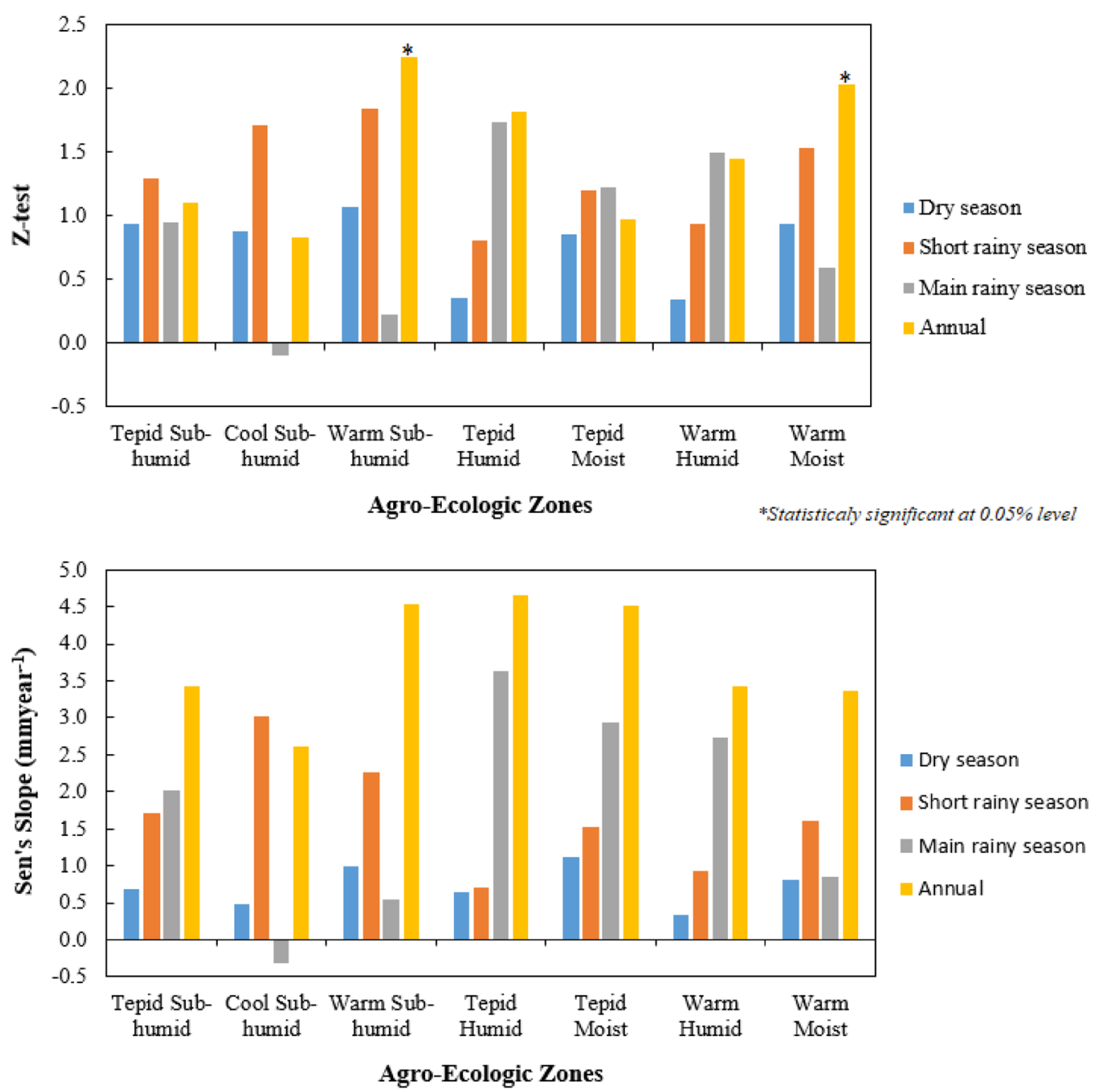

Fig. 2 Z-test (top) and Sen's slope (bottom) of rainfall trend analysis 


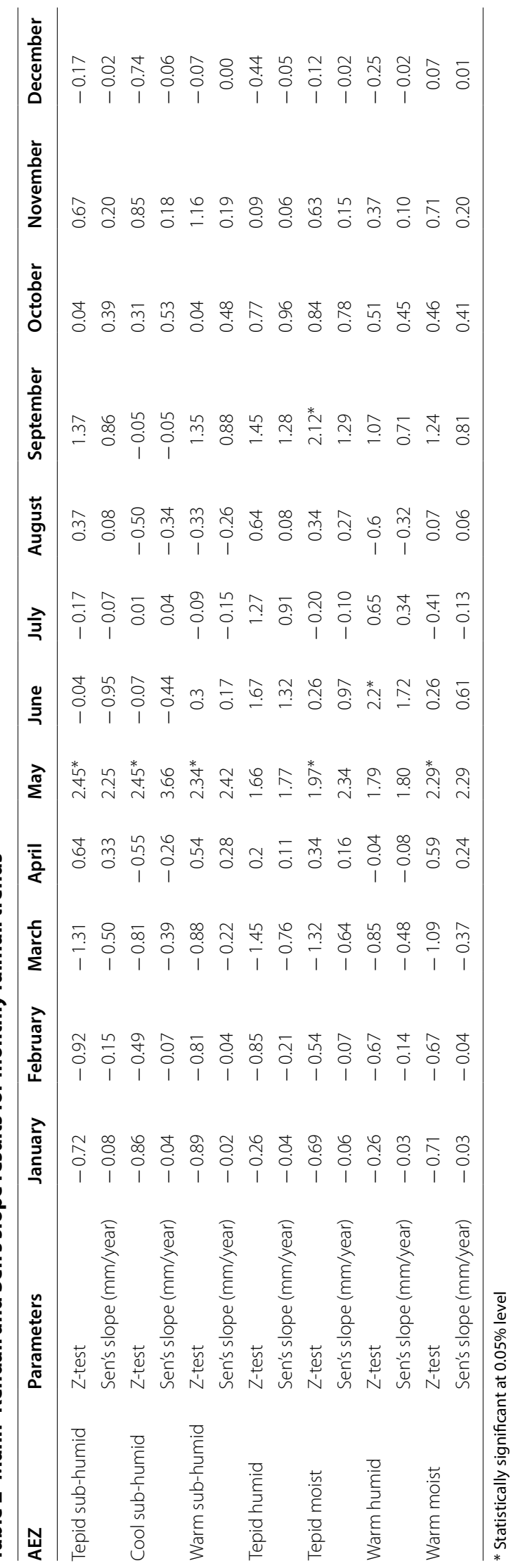


seasonal timescales. Also, the magnitude of the trend was higher for annual timescale compared to that of the season where the highest slope trend was observed for the tepid humid zone (i.e., $4.65 \mathrm{~mm} /$ year). For the monthly timescale, rainfall in May was significantly increased for most climatic zones where the highest rate was observed for the cool sub-humid climatic zone (i.e., $3.66 \mathrm{~mm} /$ year). Another important finding of the trend analysis is that there appears a seasonal shift in rainfall for the DRB. According to the study, rain begins early in May, declines in June (e.g., in tepid sub-humid and cool sub-humid zones) and extends longer than usual to the end of October in all climatic zones.

\section{Historic temperature trend analysis}

Figure 3 shows the maximum temperature trend results for the seasonal and annual timescales. The seasonal and mean annual maximum temperature was generally showed increasing for the DRB during the last three decades. However, only the main and short rainy seasons showed increasing trends. Accordingly, increasing maximum temperature trends were observed for warm subhumid, tepid moist and warm moist zones during the main rainy season. Nevertheless, increasing trends were observed during the short rainy season for the warm subhumid and warm moist zones. The slope of the trends was higher during the short rainy season for all climatic zones except for the tepid moist zone. Spatially, the cool sub-humid zone is relatively warmer during the seasonal and annual timescales. Overall, the increasing maximum temperature was observed for the DRB where the magnitude and trends vary spatiotemporally (Fig. 3).

The results of the monthly maximum temperature trend results are presented in Table 3. The result generally showed increasing maximum temperature of all months for all climatic zones. Significantly increasing trends were observed for June, July and August for all climatic zones except for the warm humid, tepid humid and cool sub-humid, respectively. Overall, February and March warm at a higher rate for all zones where the cool sub-humid zones warm at a higher rate compared to the other zones (Table 3).

The seasonal and annual trend results for the minimum temperature are shown in Table 4 . The result showed increasing seasonal and mean annual minimum temperature for the DRB. For the annual time scale, significantly increasing trends were observed for all zones except for the tepid sub-humid, warm humid and warm moist. Likewise, increasing trends were observed for tepid moist and warm moist zones during the dry season and for the cool sub-humid and tepid humid zones during the short rainy season. For the main rainy season, significantly increasing trends were observed for tepid sub-humid, tepid moist and warm moist zones. Overall, the magnitude of the trends for all zones was highest during the main rainy season while the cool sub-humid experienced relatively more warming (Fig. 4).

Table 4 shows the monthly minimum temperature trend results. Accordingly, the increasing minimum temperature was observed for all months and climatic zones except for tepid moist (for May and March) and warm moist (for December). Minimum temperature of July, August, September and October showed increasing trends for the tepid sub-humid, warm sub-humid, tepid moist and warm moist zones. Spatially, a higher slope trend was observed for the cool sub-humid zones for all months except for January, February, April and August where the warm humid and tepid humid experienced more warming (Table 4).

Generally, the result showed a higher slope trend of the minimum temperature for all AEZs compared to that of the maximum temperature. Agro-ecologically, the highest increasing rate was observed for the cool sub-humid compared to the other climatic zones while the warm moist zone experienced the lowest increasing rate. In summary, the cool sub-humid climatic zone experienced more warming compared to the other climatic zones whereas the warm moist zone was relatively stable in terms of temperature trend. Temporally, the highest increasing rate was observed during the main rainy season for minimum temperature and during the short rainy season for maximum temperature (Figs. 3 and 4, and Tables 3 and 4). The higher increasing rate of the minimum temperature during the main rainy season affirms warming of the DRB during the past three decades.

\section{Future rainfall trend analysis}

Future rainfall trend analysis for the annual, seasonal and monthly timescales are shown in Table 5. As the GCMRCM model performance varies from model to model, the rainfall trend analysis was based on the better performing models such as EC-EARTH, MIROC and ensemble mean models (Table 1). Accordingly, the MIROC and EC-EARTH models showed increasing annual rainfall trends while the ensemble mean model showed decreasing trend. Likewise, all the models detected decreasing rainfall trends for the dry and short rainy seasons while MIROC model detected increasing rainfall trend for the main rainy season. Significantly increasing rainfall trend was captured for the main rainy season by the MIROC model. For the monthly timescale, the three models showed decreasing rainfall trends for February, April and October while increasing trends for June, July and December. Statistically significant decreasing rainfall trend was 


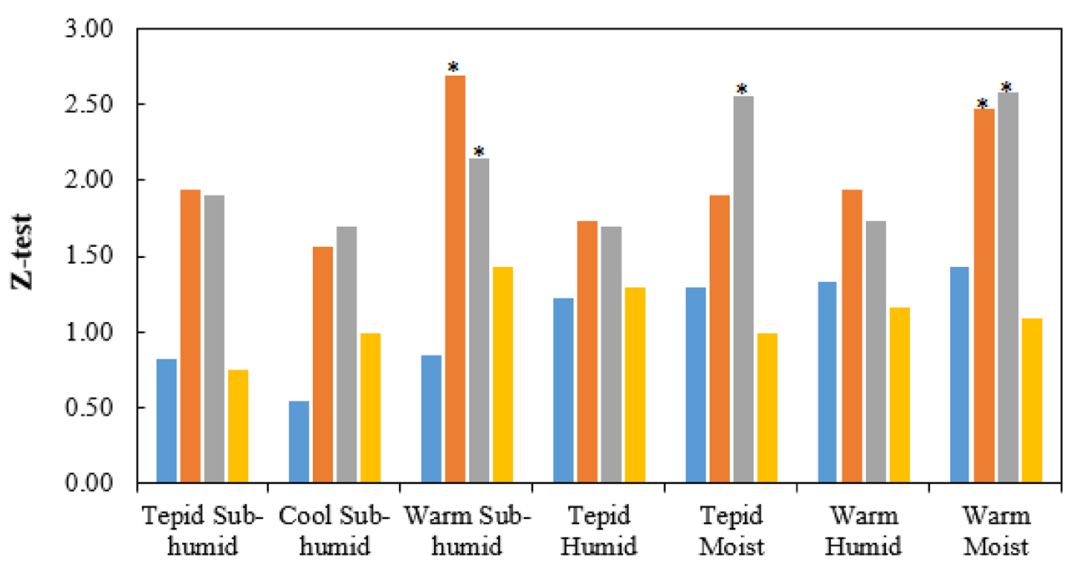

匹 Dry season

- Short rainy season

- Main rainy season

annual

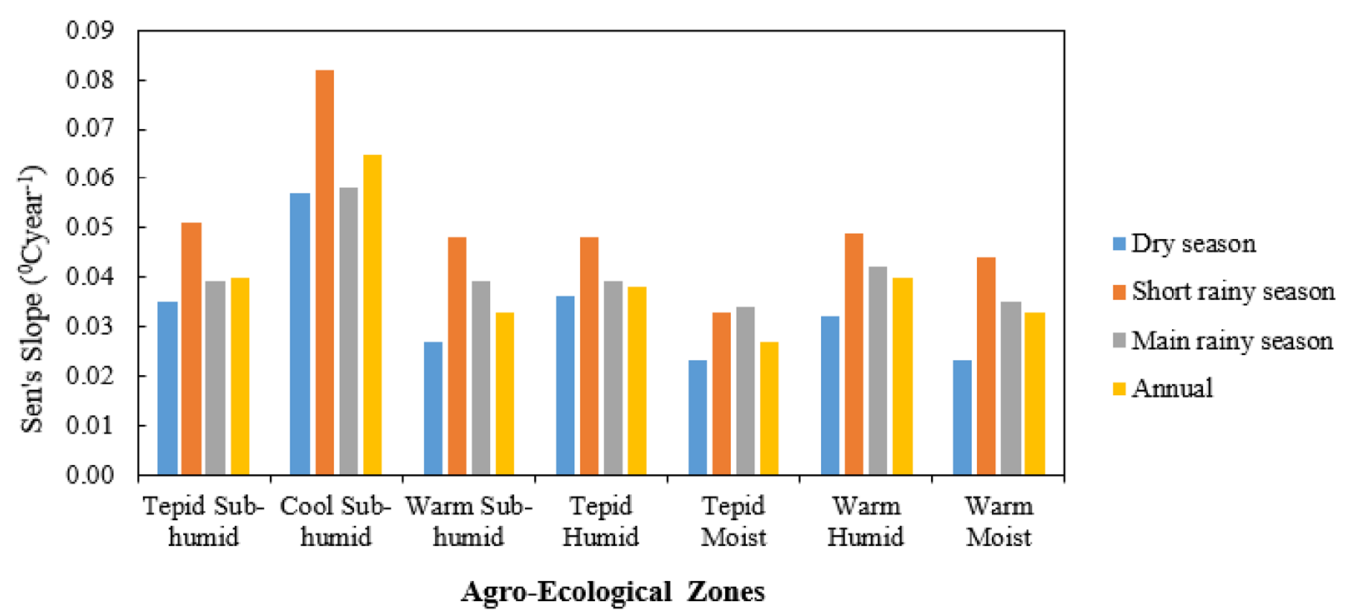

Fig. 3 Z-test (top) and Son's slope (bottom) of maximum temperature

detected by the ensemble mean model for April while the MIROC and ensemble models detected a significantly increasing trend for July. Rainfall trends in the other months were not consistent among the models (Table 5).

The better performing EC-EARTH model did not capture rainfall trends for all timescales for the DRB. Overall, the GCM-RCMs considered in this study did not show clear rainfall trends for the coming 30 years. Rainfall for the DRB, generally, will decreases for the dry season, short rainy season and annual timescales while will increases for the main rainy season in the future.

\section{Future temperature trend analysis}

The results of the future maximum and minimum temperature trends for monthly, seasonal and annual timescales are presented in Tables 6 and 7, respectively. All the models considered in this study showed increasing temperature for all timescales. Statistically significant increasing trends were observed for all seasons and annual timescales except for the main rainy season by the MIROC model. For monthly timescale, significantly increasing trends for January, February, March, November and December were captured by EC-EARTH, GFDLESM2M and ensemble mean models (Table 6).

All the models considered in this study showed significantly increasing minimum temperature trends for all seasons and annual timescales. For the monthly timescale, EC-EARTH and ensemble mean models showed significantly increasing trends for all months. Besides, the GFDL-ESM2M model showed a significantly increasing trend for all months except for January, April, November and December (Table 7). Overall, the result showed minimum temperature will increase more than that of the maximum temperature for the DRB in the coming three decades. This is similar to past trends. Therefore, the warming of the DRB will continues in the future.

\section{NDVI trend analysis}

Figure 5 shows the annual and seasonal NDVI trend results for the various AEZs of the DRB. The result 


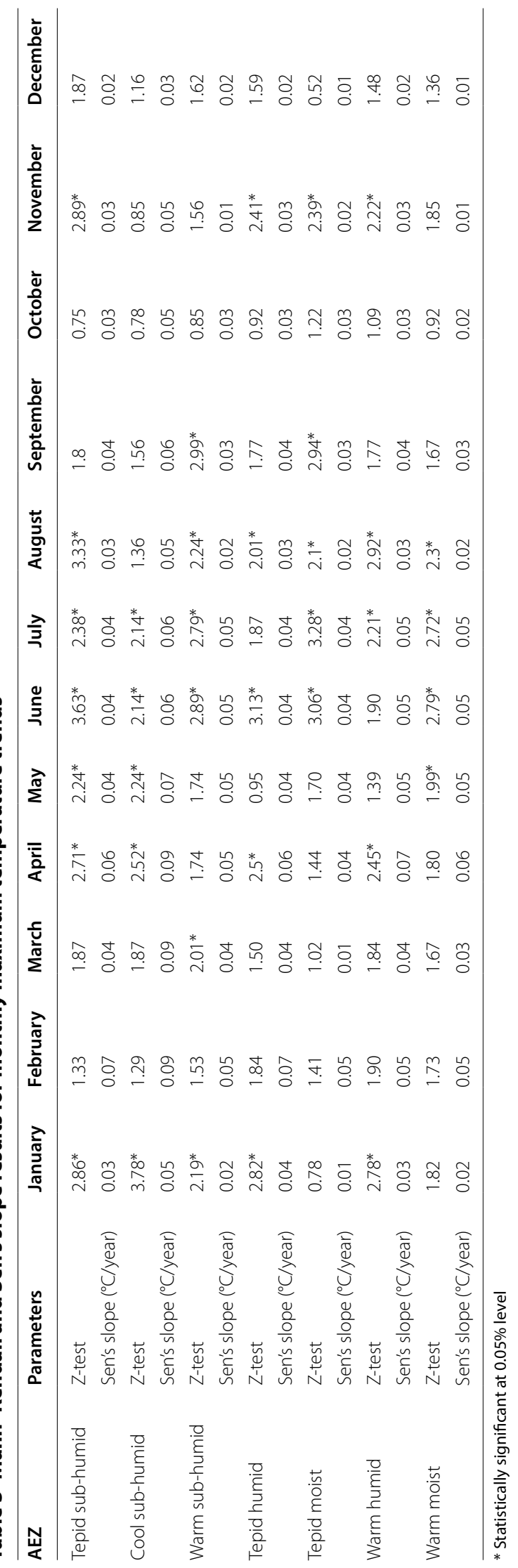




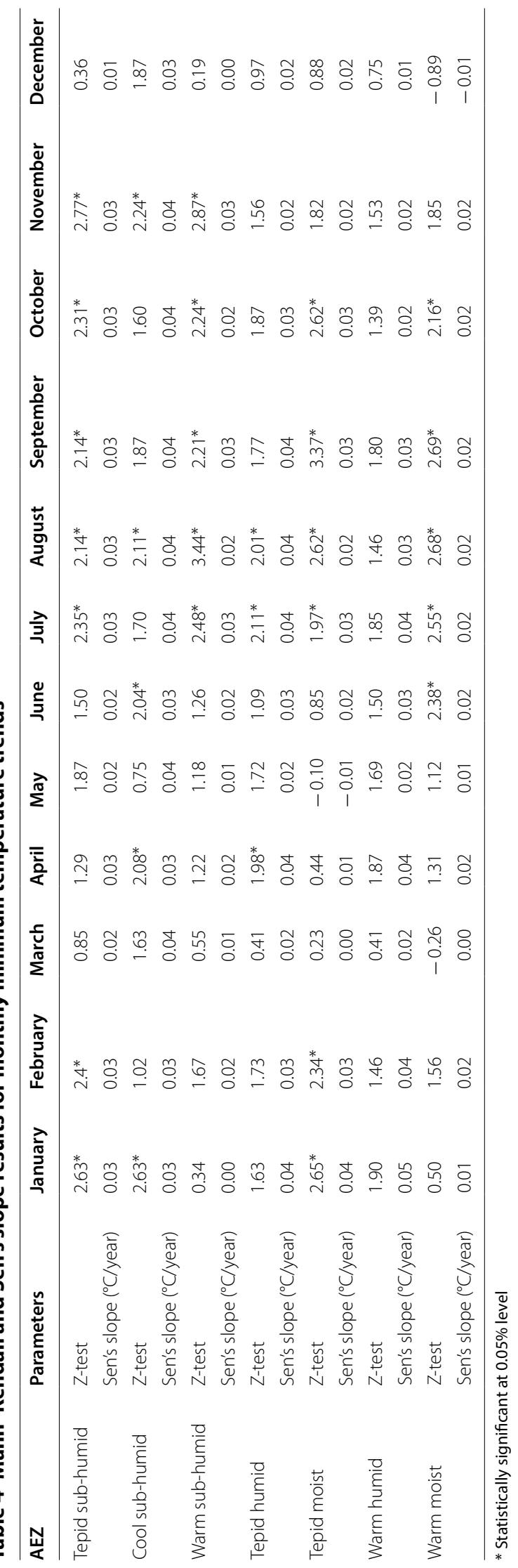




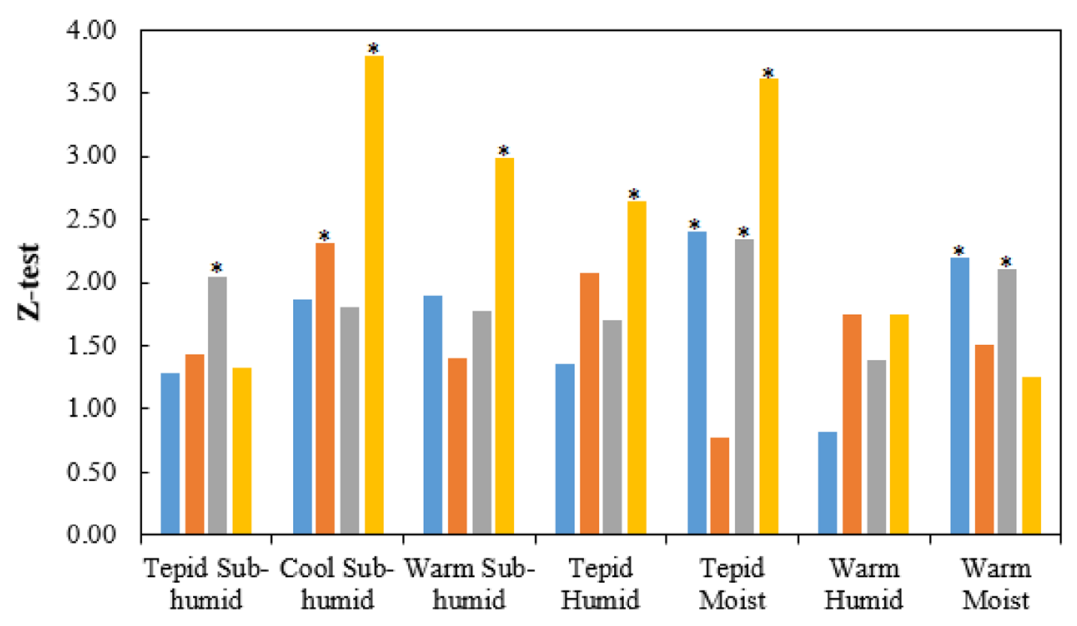

Dry Season

- Short rainy season

- Main rainy season

annual

Agro-Ecological Zones

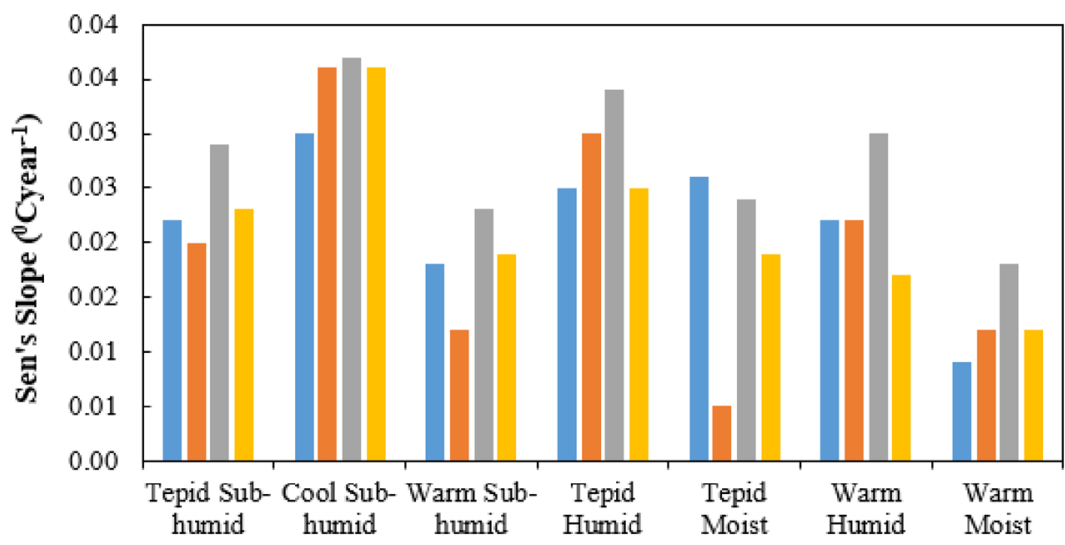

Dry Season

- Short rainy season

- Main rainy season

Annual

Agro-Egological Zones

Fig. 4 Z-test (top) and Son's slope (bottom) of minimum temperature

showed increasing NDVI trends for tepid sub-humid, warm sub-humid, tepid moist and warm moist climatic zones at the annual timescale. For the main rainy season, increasing trends were observed for tepid subhumid, warm sub-humid, tepid moist and warm moist zones. Similarly, the NDVI showed increasing trends during the short rainy season for the warm sub-humid and warm moist climatic zones. However, no trends were observed for the cool sub-humid, tepid humid and warm humid climatic zones for the annual and seasonal timescales. The slope of the trends was $\leq 0.002$ year $^{-1}$ for the annual and seasonal timescales. This implies that vegetation greenness change in the DRB was gradual and not substantial. Besides, the mean value of the NDVI for most parts of the study area was $>0.5$ showing that the DRB was covered with green vegetation.

The monthly NDVI trend analysis results are presented in Table 8 . The results of the trend analysis showed increasing trends for some months and decreasing for the other months. For example, NDVI of January and February showed increasing trends for tepid sub-humid and warm moist climatic zones. Also, the NDVI showed an increasing trend during August for all climatic zones except for the tepid humid and warm humid zones. However, no NDVI trends were observed for the tepid humid and warm humid climatic zones during all the months. However, decreasing NDVI trends of March, April and December were observed during for the tepid sub-humid climatic zone. Similar to the annual and seasonal timescales, the slopes of the trends were $\leq 0.002$ year $^{-1}$ for all the months.

Besides, basinwide NDVI analysis showed an increasing trend for the dry season and annual timescales. Moreover, a statistically significant increasing trend was observed only for the warm moist climatic 
Table 5 Mann-Kendall and Sen's slope results for projected rainfall trends

\begin{tabular}{|c|c|c|c|c|c|c|c|c|c|c|c|c|}
\hline & MPI-ESI & M-LR & MIROCS & & HadGEI & M2-ES & GFDL-E & ESM2M & EC-EAR & RTH & Ensemb & le mean \\
\hline & Z-test & $\begin{array}{l}\text { Sen's slope } \\
\text { (mm/year) }\end{array}$ & Z-test & $\begin{array}{l}\text { Sen's slope } \\
\text { (mm/year) }\end{array}$ & Z-test & $\begin{array}{l}\text { Sen's slope } \\
\text { (mm/year) }\end{array}$ & Z-test & $\begin{array}{l}\text { Sen's slope } \\
\text { (mm/year) }\end{array}$ & Z-test & $\begin{array}{l}\text { Sen's } \\
\text { slope }\left({ }^{\circ} \mathrm{C} /\right. \\
\text { year) }\end{array}$ & Z-test & $\begin{array}{l}\text { Sen's } \\
\text { slope }\left({ }^{\circ} \mathrm{C} /\right. \\
\text { year) }\end{array}$ \\
\hline January & 0.02 & 0.00 & -1.07 & -0.04 & 0.02 & 0.00 & -0.70 & -0.01 & 0.85 & 0.03 & -0.64 & -0.02 \\
\hline February & -0.45 & -0.03 & -0.95 & -0.12 & -0.98 & 0.00 & 1.30 & 0.04 & -1.38 & -0.18 & -1.29 & -0.06 \\
\hline March & -0.95 & -0.18 & 0.11 & 0.04 & 0.87 & 0.02 & -0.98 & -0.07 & -0.73 & -0.17 & -0.95 & -0.08 \\
\hline April & -1.50 & -0.64 & -1.44 & -1.26 & -0.45 & -0.13 & 1.47 & 0.49 & -1.19 & -1.06 & $-2.43^{*}$ & -0.47 \\
\hline May & $-2.31^{*}$ & -1.40 & 0.51 & 0.44 & -0.42 & -0.32 & 1.47 & 0.49 & 0.14 & 0.17 & -0.05 & -0.03 \\
\hline June & $-2.03^{*}$ & -1.34 & 1.56 & 1.25 & -1.97 & -1.39 & 1.32 & 1.28 & 0.70 & 0.48 & 0.17 & 0.05 \\
\hline July & -0.14 & -0.17 & $2.62^{*}$ & 2.69 & 1.22 & 1.04 & $2.06^{*}$ & 0.96 & 0.82 & 1.10 & $2.03^{*}$ & 0.86 \\
\hline August & 0.60 & 0.60 & 0.51 & 0.42 & 0.14 & 0.21 & 1.26 & 0.87 & -0.33 & -0.20 & 0.76 & 0.25 \\
\hline September & -0.98 & -0.70 & -0.17 & -0.19 & -1.63 & -1.33 & 0.54 & 0.23 & 0.08 & 0.10 & -1.56 & -0.59 \\
\hline October & 0.79 & 0.50 & -0.98 & -0.47 & 1.41 & 0.31 & -0.39 & -0.26 & -0.11 & -0.04 & -0.64 & -0.16 \\
\hline November & -0.42 & -0.04 & 0.05 & 0.00 & 0.15 & 0.00 & 0.11 & 0.07 & -0.14 & -0.02 & 0.14 & 0.02 \\
\hline December & 1.04 & 0.01 & 1.94 & 0.06 & -0.16 & 0.00 & -0.14 & -0.02 & 0.73 & 0.04 & 0.11 & 0.01 \\
\hline Dry season & 0.73 & 0.44 & -1.41 & -0.56 & 1.07 & 0.25 & -0.45 & -0.59 & -0.36 & -0.45 & -0.95 & -0.19 \\
\hline Short rainy season & $-2.87^{*}$ & -2.20 & -0.70 & -0.96 & -0.73 & -0.38 & 1.13 & 0.88 & -0.73 & -0.71 & -1.63 & -0.69 \\
\hline Main rainy season & -0.91 & -1.87 & $2.09^{*}$ & 3.26 & -1.22 & -2.00 & $2.40^{*}$ & 2.95 & 0.60 & 0.92 & 0.82 & 0.71 \\
\hline Annual & $-2.46^{*}$ & -3.31 & 0.45 & 0.90 & -1.56 & -2.64 & 1.69 & 3.54 & -0.23 & -0.48 & -0.64 & -0.48 \\
\hline
\end{tabular}

* Statistically significant at $0.05 \%$ level

Table 6 Mann-Kendall and Sen's slope results for projected maximum temperature trends

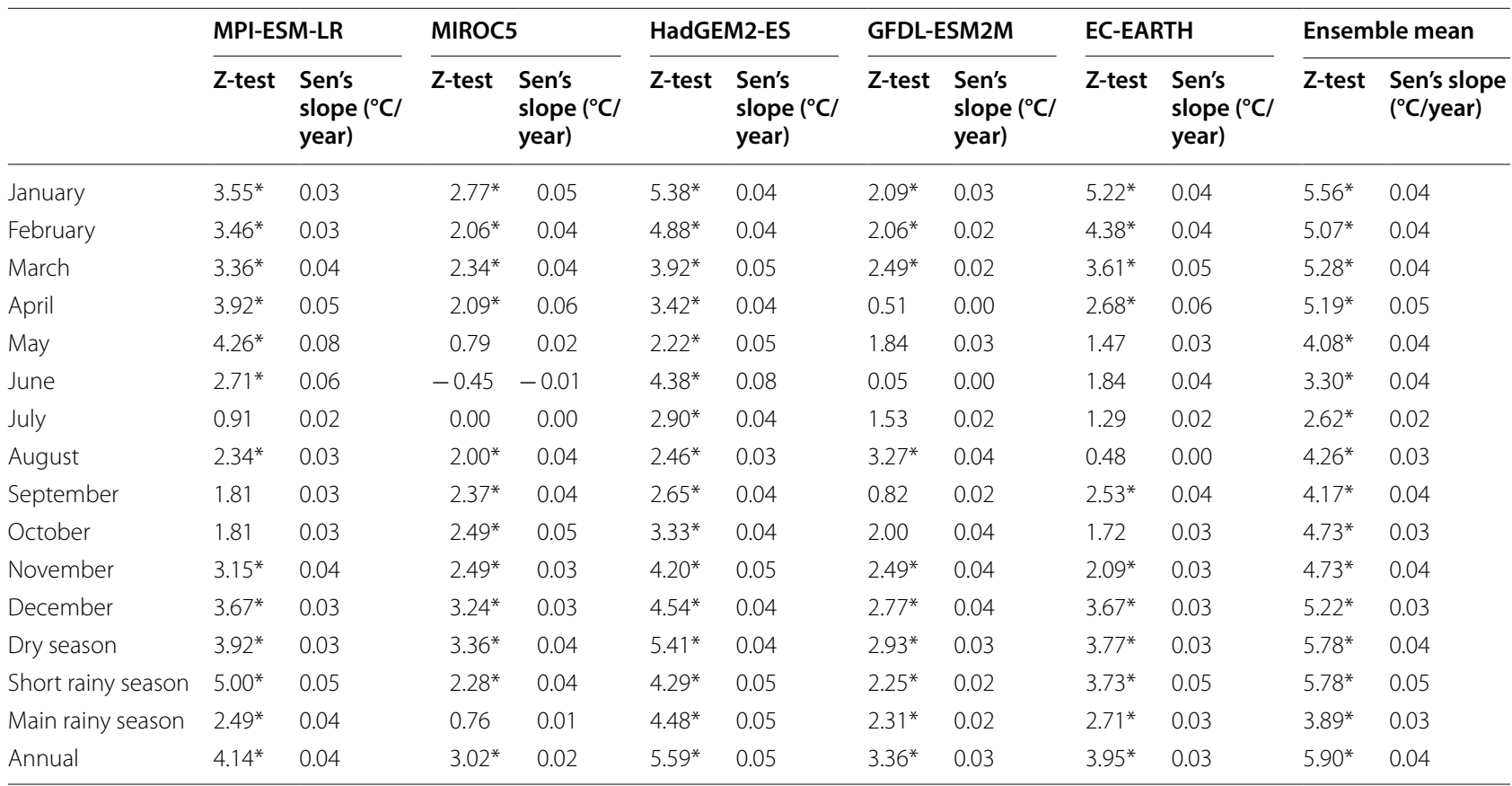

* Statistically significant at $0.05 \%$ level

zones. These imply spatial scale influences the results of NDVI trend analysis. The next section describes the spatiotemporal dynamics of climate and NDVI and how they are related.

\section{The spatial relationship between NDVI and climate} variables

The spatial relationships between average climate variables (i.e., rainfall, minimum and maximum temperature) 
Table 7 Mann-Kendall and Sen's slope results for projected minimum temperature trends

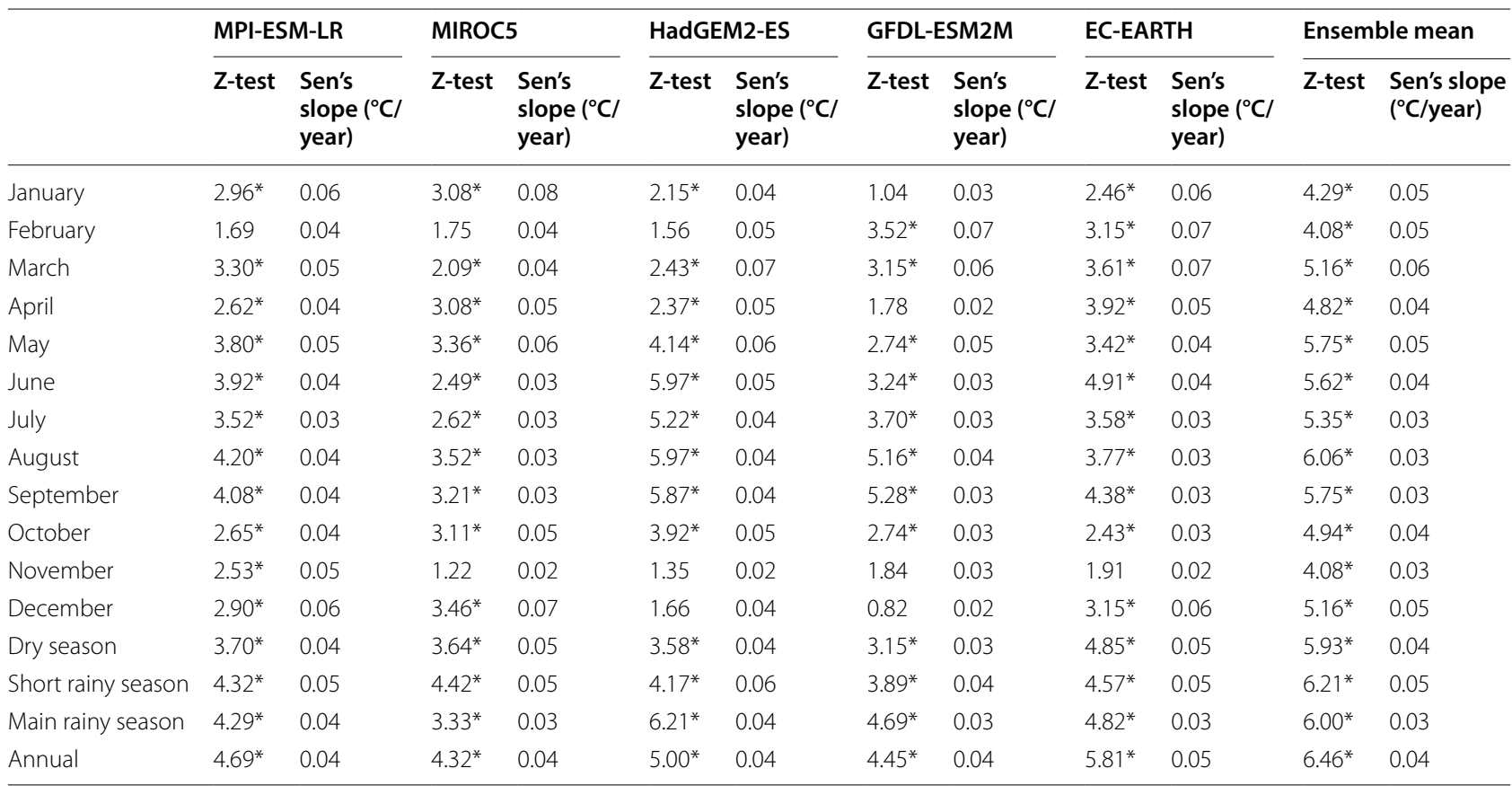

* Statistically significant at $0.05 \%$ level

and NDVI are shown in Table 9. Model parameters described in the table are the mean values of the GWR parameters computed at a local scale. The residuals indicate uncertainty in the model predictions. The lower the residuals the better the predictive power of the model. Moreover, Moran's index close to zero represents that model residuals are independent, which shows no spatial autocorrelation (Propastin et al. 2008).

The result showed that the NDVI was positively related to rainfall with a mean coefficient of 0.0002 while it is negatively related to minimum and maximum temperatures with mean coefficients of -0.015 and -0.007 , respectively. However, the $\mathrm{r}^{2}$ between rainfall and NDVI was 0.62 while it was 0.45 and 0.58 for maximum and minimum temperature, respectively. The results showed that climate variables are good in explaining the temporal and spatial variations of NDVI for the DRB. However, the strength of the relationship varies spatially and from variable to variable (Fig. 6). As $\mathrm{r}^{2}$ values greater than 0.5 indicate a satisfactory predictive capability of the GWR model (Propastin et al. 2008), the results imply that NDVI was more strongly related to rainfall than with temperature for the DRB. On the other hand, minimum temperature more explains the dynamics of NDVI than the maximum temperature. Spatially, the NDVI-climate variables relationships were stronger in the highland (i.e., southern) parts of the study area than in the lowland (i.e., northern) parts (Fig. 6). This implies the underlying biophysical conditions that influence the relationship between NDVI and climate variables are different within the DRB; the highland and lowland parts of the basin have different biophysical conditions. Moreover, the result shows spatial heterogeneity of the relationship between NDVI and climate variables. As such, the GWR model parameters such as coefficients and residuals were spatially different for the DRB.

Accordingly, the spatially distributed coefficients and model residuals for the NDVI-minimum temperature relationships are shown in Fig. 7. The result showed a strong negative relationship for the southern part and a weak relationship for the central parts of the DRB. Likewise, residuals of the GWR model are spatially different revealing that the model overestimated in some parts and underestimated in other parts of the study area.

Likewise, the relationship between maximum temperature and NDVI is spatially variable. The negative relationship is stronger in the southern and central parts of the study area, which is consistent with the pattern observed between the NDVI-minimum temperature. Similarly, the residual of the model is spatially heterogeneous where the GWR model overestimates in the southern and western parts and underestimates in the central part of the study area (Fig. 8).

The strength of the NDVI-rainfall relationship increased from the northern part to the southern part of the study area like in the NDVI-temperature relationship (Fig. 9). The spatially variable residuals revealed that the predictive power and factors affecting vegetation 


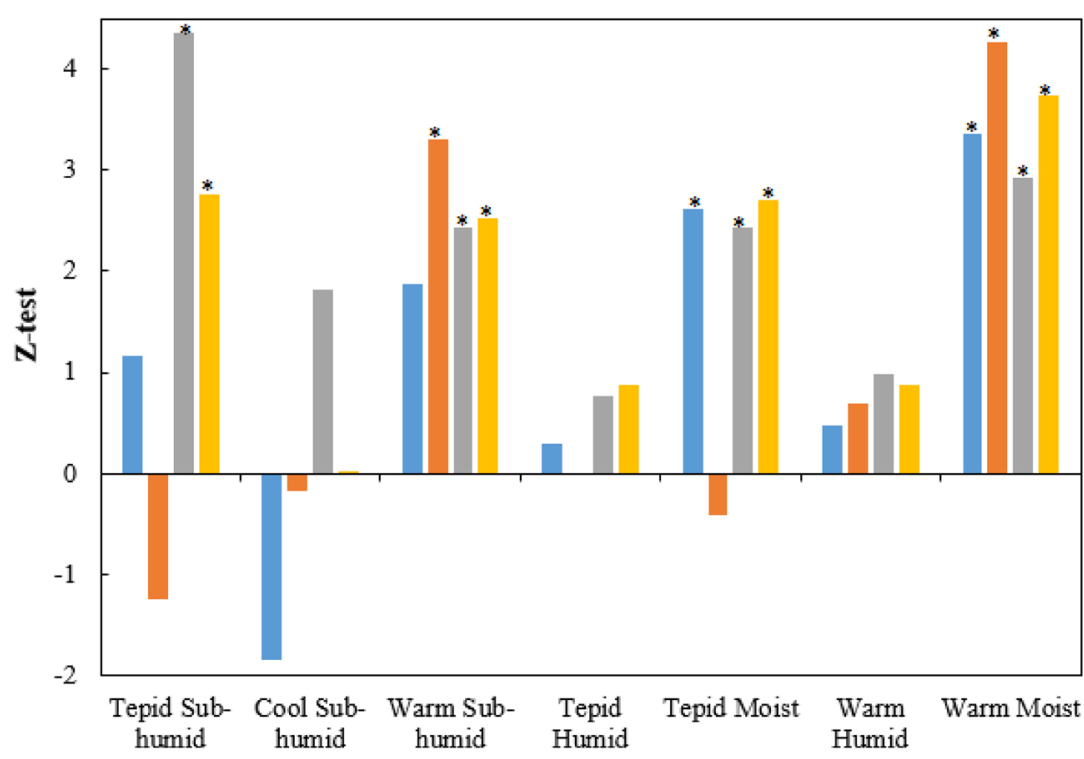

Dry season

$\square$ Short rainy season

Main rainy season

annual

Agro-Ecologic Zones

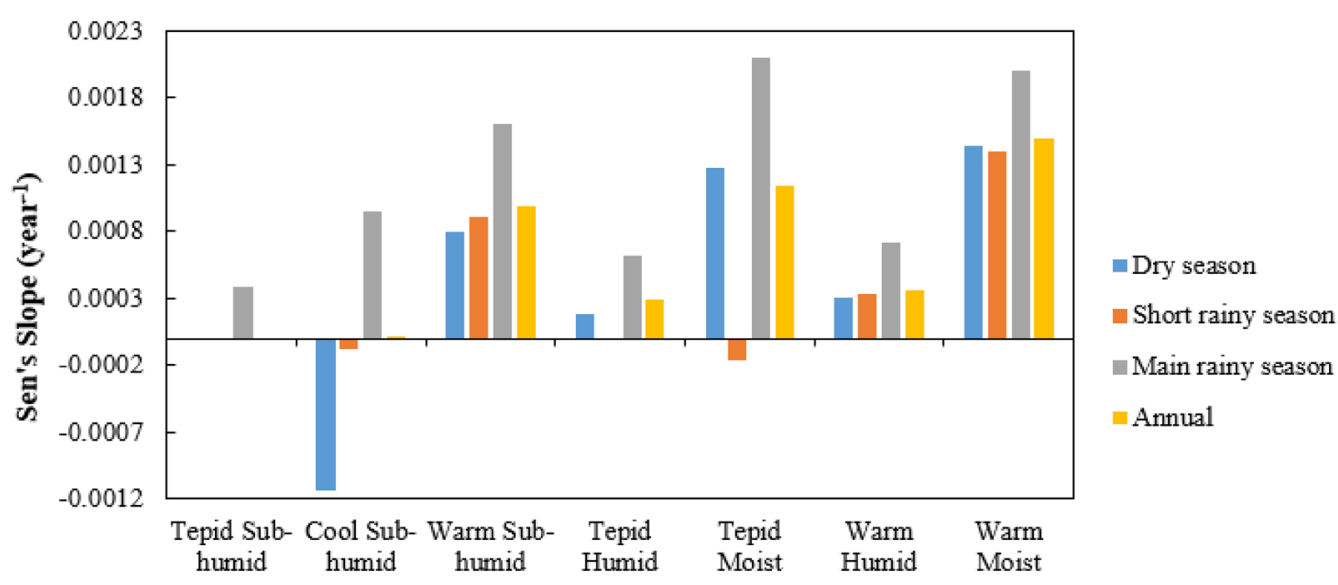

Agro-Ecologic Zones

Fig. 5 Z-test (top) and Son's slope (bottom) of NDVI

conditions are different for the different parts of the study area. Overall, the results of local $\mathrm{r}^{2}$ and coefficients revealed the strong relationship of the NDVI-climate variables at the highland (southern) parts than in the lowland (northern) for the DRB.

\section{Discussion}

\section{Spatiotemporal climate trends}

This study showed that the rainfall trend results vary spatially within AEZs and from month to month. Relatively, the seasonal and annual rainfall showed more consistent trend results. The annual and seasonal rainfall for the DRB generally showed increasing for all climatic zones except for the cool sub-humid zone that showed declining for the main rainy season. The increasing rainfall for all AEZs during the dry season indicated declining rainfall in January, February and December where more than balanced by increases in October and November. Likewise, rainfall increased in May but declined in March and April for the short rainy season. These mean that dry season rainfall mainly occurred during October whereas the short rainy season mainly receives rainfall during May. The results imply that the DRB is generally becoming more wet, which has positive impacts on agricultural production and water resources availability. The finding is consistent with previous studies that reported the southwestern part of the upper Blue Nile basin, where the DRB 


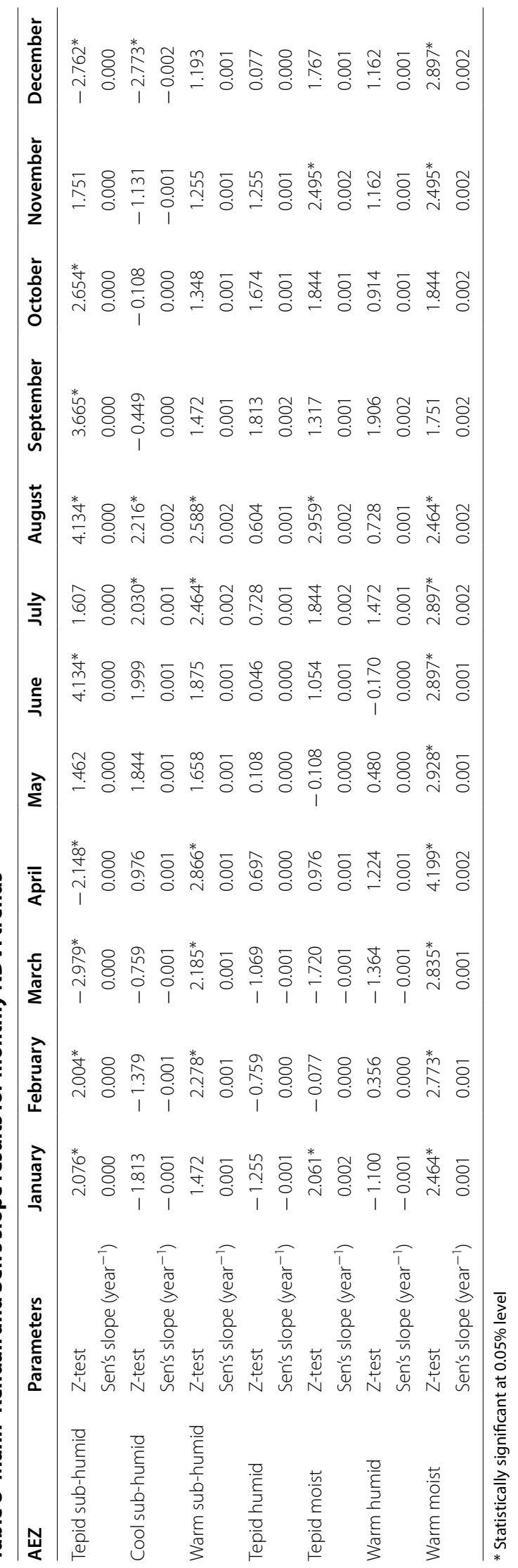


Table 9 Geographically weighted regression model results

\begin{tabular}{|c|c|c|c|c|c|c|c|c|c|c|c|c|}
\hline \multirow[t]{2}{*}{ Explanatory variables } & \multicolumn{3}{|c|}{$\beta_{0}$ (intercept) } & \multicolumn{3}{|c|}{$\beta$ (coefficient) } & \multirow[t]{2}{*}{ Adj $R^{2}$} & \multirow[t]{2}{*}{ Moran's index } & \multirow[t]{2}{*}{ RMSE } & \multicolumn{3}{|c|}{ Residual $(\varepsilon)$} \\
\hline & Min & Max & Mean & Min. & Max. & Mean & & & & Min. & Max & Mean \\
\hline Rainfall & 0.26 & 0.42 & 0.35 & $10^{-4}$ & 0.0002 & 0.0002 & 0.62 & 0.19 & 0.03 & -0.09 & 0.05 & -0.001 \\
\hline Maximum temperature & 0.71 & 0.91 & 0.80 & -0.01 & -0.004 & -0.007 & 0.45 & 0.41 & 0.05 & -0.08 & 0.07 & 0.002 \\
\hline Minimum temperature & 0.73 & 0.94 & 0.83 & -0.02 & -0.01 & -0.015 & 0.58 & 0.22 & 0.03 & -0.07 & 0.06 & 0.0001 \\
\hline
\end{tabular}

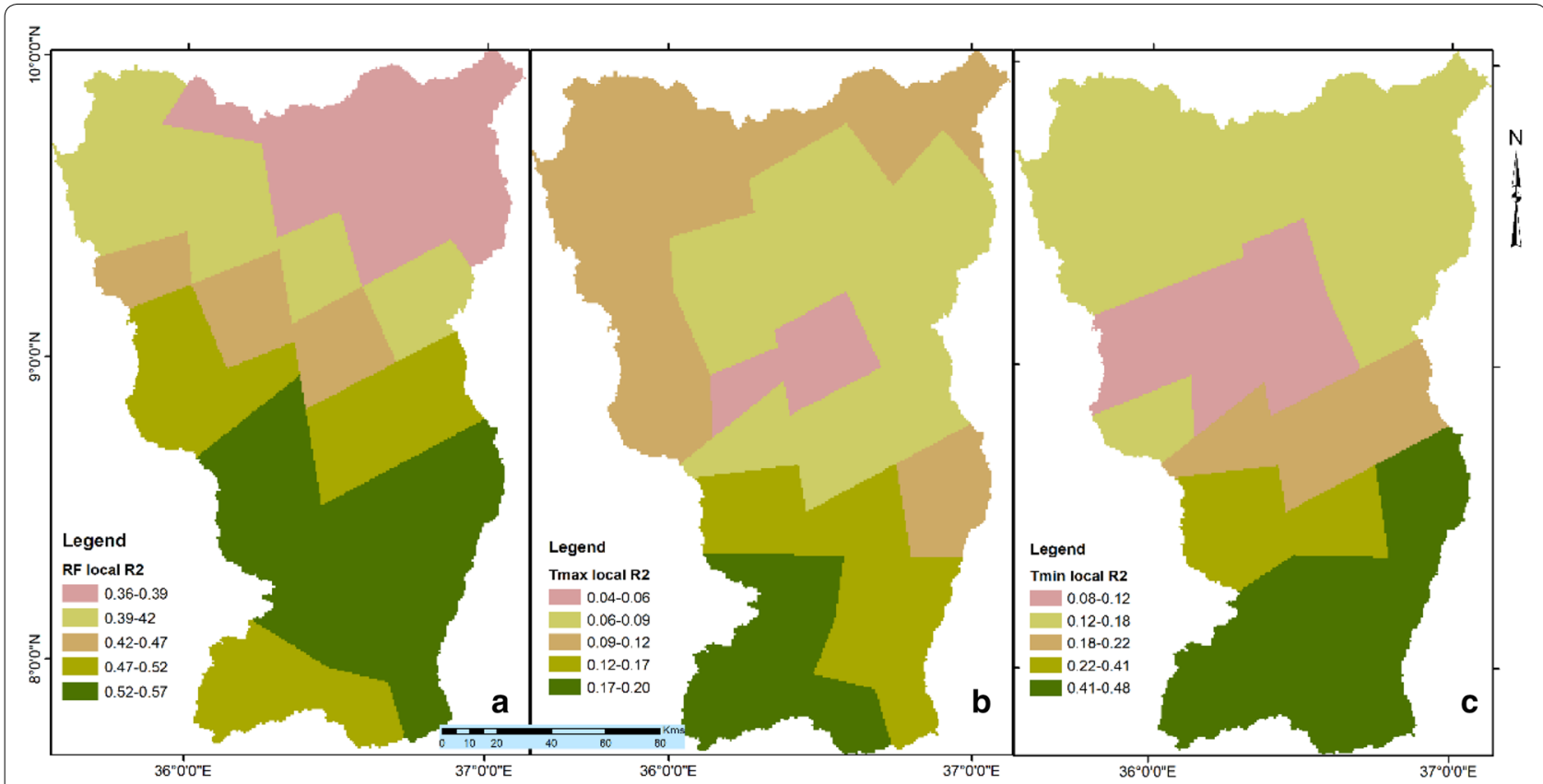

Fig. 6 Spatial variation of local $r^{2}$ for rainfall (a), maximum temperature (b) and minimum temperature (c)

is located, is becoming more wetting (e.g., Mellander et al. 2013; Brown et al. 2017; Weldegerima et al. 2018; Worku et al. 2018).

Moreover, the seasonal shift in rainfall reported in this study is consistent with previous studies for the upper Blue Nile basin (Berhane et al. 2014; Vincent et al. 2018). According to this study, rainfall begins early in May, declines in June (e.g., in tepid sub-humid and cool subhumid zones) and extending longer than usual to the end of October. This has significant negative impacts primarily on rain-fed agriculture as agricultural practices in the study area are highly dependent on the rainy season's rainfall. The starting and ending of the rainy season in Ethiopia affects planning, performance and management of agricultural operations and usually, leads to a poor harvest and/or complete crop failure (Gebre et al. 2013). For example, in the DRB, common crops such as Teff (Eragrostis), Maize, Sorghum and Millet are mainly planted during late June and harvested during the end of October. These imply that the seasonal shift affects crop yields by delaying plantation and extending harvesting time. Early plantation in May might result in crop failure resulted from declining rainfall in June while plantation in June might result in yield reduction due to the reduced rainfall in June and/or extended rainfall until the end of October, which is the harvesting time in the study area. As such, farmers should be advised to plant a short growing period crops in May and/or shift plantation time for long growing period crops to early July.

On the other hand, the DRB is warming with an average temperature increasing rate of about $0.45^{\circ} \mathrm{C}$ per decades, which is comparable with the global warming rate (i.e., $0.6{ }^{\circ} \mathrm{C}$ for the past century) and East African mean annual temperature increasing rate (i.e., $0.35{ }^{\circ} \mathrm{C}$ per decades) (Musau et al. 2018). Also, the findings of the study were consistent with a study reported for the upper Blue Nile (Tekleab et al. 2013; Worku et al. 2018; Asfaw et al. 2018). Overall, the DRB experienced wetting and warming in the past 30 years. This has a positive impact on crop production, if the plantation season is carefully selected, while it 

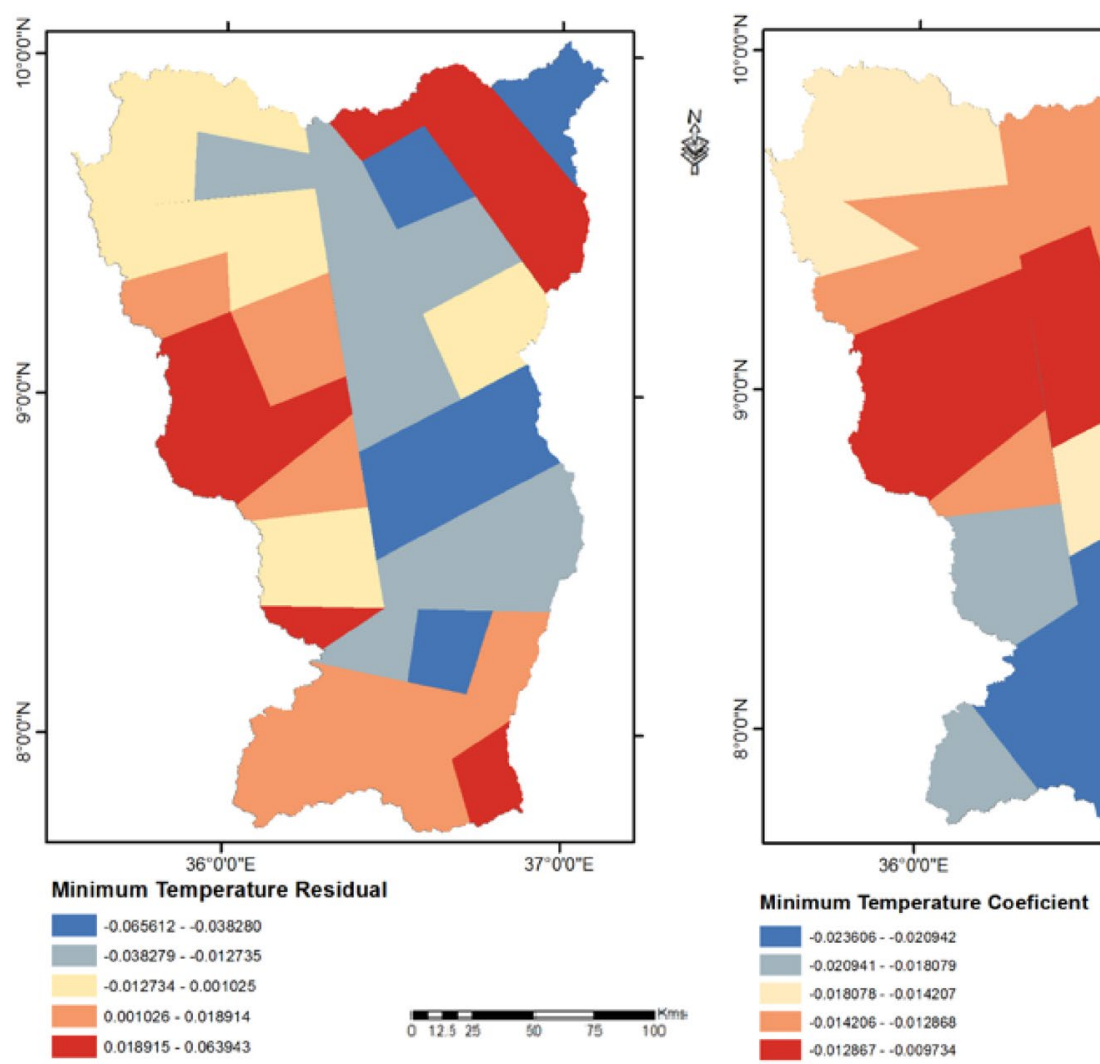

Fig. 7 GWR model residuals (right) and coefficients (left) for NDVI-minimum temperature

has a negative consequence for water resource availability (e.g., reservoirs) by increasing evapotranspiration loss. Moreover, the observed warming and declining rainfall trends during the main rainy season for the cool subhumid climatic zones implying negative consequences for rain-fed agriculture and water resource availability.

On the other hand, the future rainfall and temperature for the DRB were better simulated by GCM-RCMs such as EC-EARTH, GFDEL-EMS2M and MIROC5 models. This is consistent with the study for the upper Blue Nile basin where the DRB is located (Haile and Rientjes 2015). The performance of the models considered in this study is inconsistent for rainfall while consistent for temperature, which is in line with several studies (Mengistu et al. 2014; Mekonnen and Disse 2018; Bhattacharjee and Zaitchik 2015). Rainfall decreased for the annual, dry and short rainy seasons timescales and increased for the main rainy season while temperature increased for all timescales for the coming 30 years for the DRB. These changes imply negative consequences for agriculture and water resource availability. The findings are inconsistent with previous studies where warming and wetting were reported for the upper Blue Nile basin (Mekonnen and Disse 2018; Worqlul et al. 2018). The discrepancies, particularly in rainfall simulation results, are due to the differences in the spatial and timescales of the studies, types of the model used and climate scenario considered.

\section{Vegetation greenness-climate variables nexus}

The increasing NDVI trends reported in this study for most parts of the DRB seem counter-intuitive given, for example, the deforestation activities that have been taking place in the basin (Mekonnen et al. 2018). Thus, the trend result may not necessarily represent increasing vegetation cover for the study area, which implies that the GIMMS NDVI datasets does not capture forest cover change due to the saturation problem of the sensor (Yin et al. 2012; Loranty et al. 2018). Moreover, the NDVI trend results show that the GIMMS NDVI dataset do not capture local vegetation trends caused by anthropogenic effects. This implies that the GIMMS NDVI-based trend analysis can effectively describe climate-induced vegetation changes at a regional scale but not at a local scale.

Therefore, the increasing NDVI trends that were observed in the study area could be in response to (i) increase in dry season rainfall as previously described; (ii) the presence of trees and shrubs left within agricultural lands despite deforestation activities in the study area 


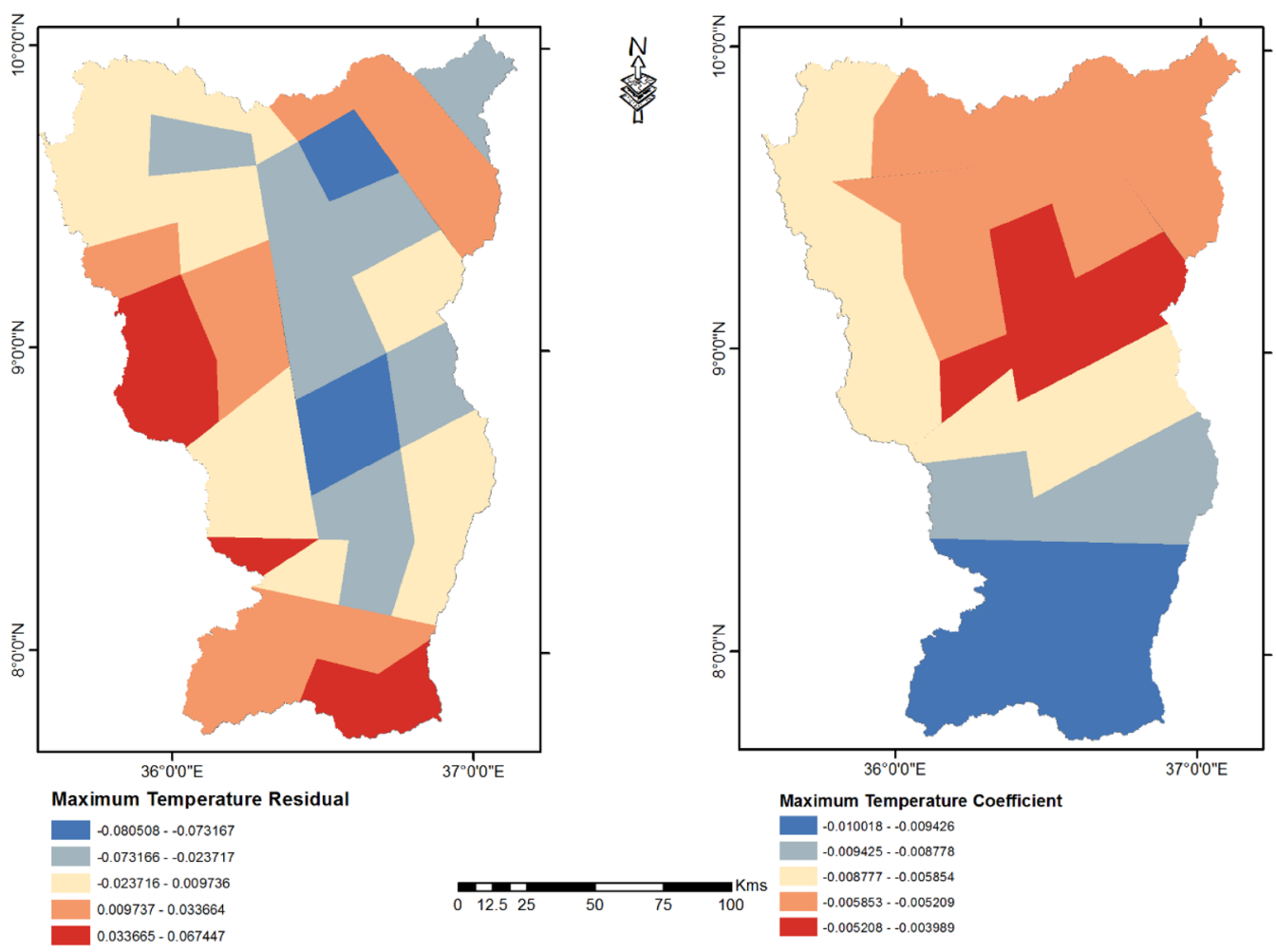

Fig. 8 GWR model residuals (right) and coefficients (left) for NDVI-maximum temperature

and (iii) the perennial crops (e.g., Mango, Avocado and Coffee with shed trees) in the basin. Besides, the finding of this study is in line with the GIMMS-based NDVI trend analysis that reported greening of south and southwestern parts of the upper Blue Nile, where this study area is located, from 1982 to 2005 . On the contrary, the same study using MODIS data from 2006 to 2011 showed a browning vegetation cover in the basin (Teferi et al. 2015). The inconsistency of the results could be due to the difference in the types of data sources.

The strength and sign of the NDVI-climate relationships are spatially variable for the DRB. Such non-stationarity relationships, which may be controlled by the underlying environmental factors such as vegetation, soil and land cover types, are effectively analyzed using the GWR techniques. The relatively lower $r^{2}$ values show that other factors are also responsible for the vegetation dynamics observed in the study area. The result indicates that besides rainfall and temperature, anthropogenic and other physical factors (e.g., soil and topography) could be responsible for the vegetation dynamics observed for the basin. Moreover, the positive correlation between NDVI and rainfall indicated that vegetation greenness is dependent on water availability while the negative correlation with temperature could be due to increased evapotranspiration resulting from a higher temperature (Ji and
Peters 2004). The relationship between the NDVI-climate observed in this study is consistent with previous studies (Zhao et al. 2015; Getahun and Shefine 2015).

\section{Conclusions}

A comprehensive study that includes spatiotemporal dynamics of climate variables and vegetation greenness, and their spatial relationship provides important information for designing climate change adaptation strategies. Rainfall of the DRB generally showed increasing for the seasonal and annual timescales. However, statistically significant trends were observed only for the warm subhumid and warm moist zones for annual timescale. Nevertheless, rainfall trends for the monthly timescale showed inconsistent trends. On the other hand, significantly increasing trend of minimum and maximum temperature was observed for the DRB during all the timescales. The highest increasing rate was observed during the main rainy season for minimum temperature and during the short rainy season for maximum temperature. Spatially, the cool sub-humid climatic zone experienced more warming while warm moist is relatively stable in terms of temperature trends. This finding implies the need to analyze climate trends at a different time and spatial scales to capture reliable local trends. Overall, past climate trends showed wetting and warming for the DRB during the last 30 years. 

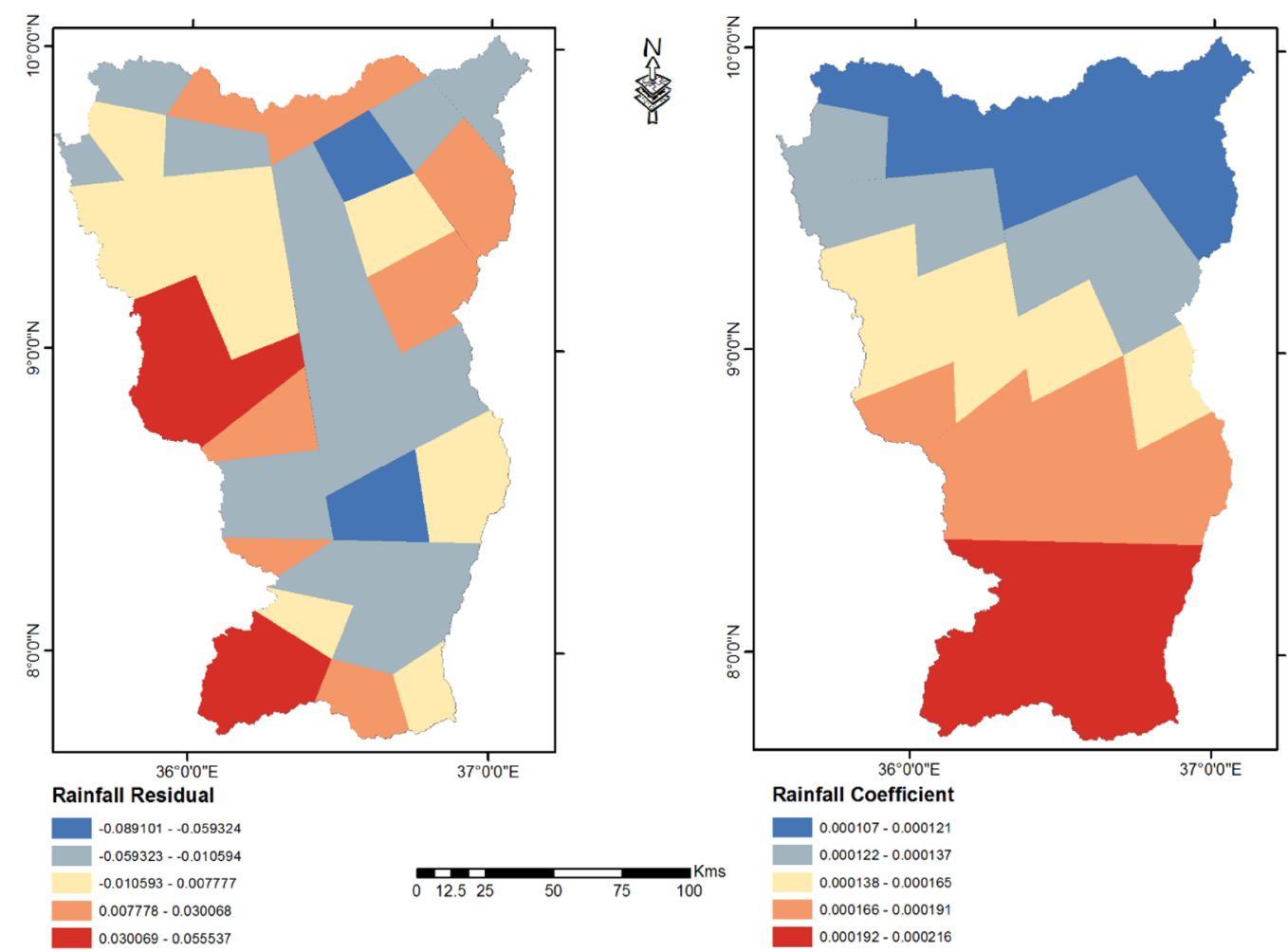

Fig. 9 GWR model residuals (right) and coefficients (left) for NDVl-rainfall

However, rainfall trends did not show clear trends in the future. It generally declined for the dry season, short rainy season and annual timescales while showed an increasing trend for the main rainy season. On the contrary, temperature showed increasing trends during all the timescales for the DRB in the coming 30 years. The minimum temperature will be increased at a higher rate compared to the maximum temperature implying warming of the study area which is the sign of climate change. Overall, the increasing temperature and variable rainfall noted in this study will have both positive and negative consequences for agricultural production and water resource availability. The warming and wetting scenario will boost agricultural production if appropriate plantation and harvesting time are selected otherwise it will result in complete crop failure and/ or yield reduction. However, the warming and declining rainfall during the dry season, short rainy season and annual timescales will result in deteriorated water resource availability while the increasing rainfall trend during the main rainy season will increase water resource availability, which may result in flooding.

On the other hand, NDVI trends for the DRB are spatiotemporally variable and generally showed greening for most timescales and AEZs. For example, no trends were observed for the cool sub-humid, tepid humid and warm humid climatic zones for all timescales. The increasing NDVI trends for the other climatic zones seem counter-intuitive given the deforestation activities that have been taking place in the basin. This implies that the GIMMS NDVI may not capture forest cover changes for the study area. Thus, the increasing trend could be in response to the increasing dry season rainfall, presence of trees and shrubs within agricultural lands and the presence of perennial crops (e.g., Mango, Avocado and Coffee with shed trees) in the basin. Moreover, since most of the deforested land was replaced by crops, vegetation changes may not be captured particularly during the main rainy season. These imply that the GIMMS NDVI-based trend analysis can effectively describe climate-induced vegetation changes at a regional scale. However, a local scale vegetation change induced by anthropogenic activities may not be captured by the dataset. The spatiotemporal dynamics of the NDVI for the DRB is positively related to rainfall while negatively related to the temperature where the strength of the relationship is higher with rainfall (i.e., $r^{2}=0.62$ ). The study also showed that the increasing temperature for the DRB will negatively affect the vegetation condition of the study area.

Generally, the study showed that climate and vegetation greenness changes vary spatially from one climatic 
zone to the other. Moreover, the spatial relationship between NDVI and climate variables also spatially variable. Thus, this study provides important information for planning and managing natural resources and designing climate change adaption strategies at a local scale. The comprehensive study that integrates multiple methods and datasets, illustrated in this paper, is vital for the agricultural and water resource sectors.

\begin{abstract}
Abbreviations
NDVI3g: normalized difference in vegetation index - 3rd generation; GWR : geographically weighted regression; CMIP: coupled model intercomparison project phase; RCP: representative concentration pathway; GCM: global climate model; OLS: ordinary least squared; AEZ: agro-ecological zone; NMA: National Meteorological Agency; ENACTS: Enhanced National Climate Timeseries Services; MODIS: moderate resolution imaging spectroradiometer; LST: land surface temperature; CHIRPS: Climate Hazards Group InfraRed Precipitations with Stations; GIMMS: global inventory, monitoring and modelling studies; NOAA: National Oceanic and Atmospheric Agency; AVHRR: advanced very high-resolution radiometer; CORDEX: coordinated regional climate downscaling experiment; WCRP: World Climate Research Program; RCM: regional climate model.
\end{abstract}

\section{Acknowledgements}

We are grateful to Ethiopian Space Science and Technology Institute for financially supporting this research. We are also grateful to NDVI3g and CHIRPS V2 providers. The National Meteorological Agency of Ethiopia is thankfully accredited for providing gridded temperature and rainfall data and ground station climate datasets.

\section{Authors' contributions}

GK conceptualize the study, analyze and interpret the data, and wrote the manuscript. MK, BG and SA revised and edited the manuscript. All authors read and approved the final manuscript.

\section{Funding}

This research received no external funding.

\section{Availability of data and materials}

The data sources used in this study includes CHIRPS (http://dx.doi. org/10.15780/G2RP4Q), NDVI3g (https://ecocast.arc.nasa.gov/data/pub/ gimms3g.v1) and future climate (https://esgf-node.Ilnl.gov). The other datasets can be provided up on request.

\section{Ethics approval and consent to participate}

Not applicable.

\section{Consent for publication}

Not applicable.

\section{Competing interests}

The authors declare that they have no competing interests.

\begin{abstract}
Author details
1 Department of Earth Sciences, Wollega University, P.O.Box 395, Nekemte, Ethiopia. ${ }^{2}$ Department of Remote Sensing, Entoto Observatory Research Center, Ethiopia Space Science Technology Institute, P.O.Box 33679, Addis Ababa, Ethiopia. ${ }^{3}$ Department of Civil and Environmental Engineering, California Polytechnic State University, San Luis Obispo, USA. ${ }^{4}$ Department of Geography and Environmental Studies, Kotebe Metropolitan University, Addis Ababa, Ethiopia. ${ }^{5}$ Department of Meteorology, University of Reading, Reading, UK. ${ }^{6}$ Department of Hydraulics and Water Resource Engineering, Jimma Institute of Technology, Jimma Unviversity, Jimma, Ethiopia.
\end{abstract}

\section{Appendix}

See Table 10.
Table 10 Description of AEZ classes

\begin{tabular}{llll}
\hline AEZ & Altitude (m.a.s.I) & Temperature $\left({ }^{\circ} \mathbf{C}\right)$ & LGP (day) \\
\hline Cool sub-humid & $1600-3200$ & $11-15$ & $181-240$ \\
Tepid moist & $1000-2000$ & $16-21$ & $121-180$ \\
Warm sub-humid & $1000-2000$ & $21-27$ & $181-240$ \\
Tepid sub-humid & $2000-28,000$ & $16-21$ & $181-240$ \\
Warm humid & $600-2200$ & $21-27$ & $241-300$ \\
Tepid humid & $2000-3000$ & $16-21$ & $241-300$ \\
Warm moist & $400-1500$ & $21-27$ & $121-180$
\end{tabular}

LGP length of growing period

Received: 11 June 2019 Accepted: 11 October 2019

Published online: 05 November 2019

\section{References}

Abtew W, Melesse AM, Dessalegne T (2009) El Niño Southern oscillation link to the Blue Nile river basin hydrology. Hydrol Process 23:3653-3660

Addisu S, Selassie YG, Fissha G, Gedif B (2015) Time series trends analysis of temperature and rainfall in lake Tana, Sub-basin Ethiopia. Environ Syst Res 4:25

Asfaw A, Simane B, Hassen A, Bantider A (2018) Variability and time series trend analysis of rainfall and temperature in northcentral Ethiopia: a case study in Woleka sub-basin. Weather Clim Extremes 19:29-41

Berhane F, Zaitchik B, Dezfuli A (2014) Subseasonal analysis of rainfall variability in the Blue Nile River basin. J Clim 27(1):325-344

Beyene T, Lettenmaier DP, Kabat P (2010) Hydrologic impacts of climate change on the Nile River Basin: implications of the 2007 IPCC scenarios. Clim Change 100:433-461

Bhattacharjee PS, Zaitchik BF (2015) Perspectives on CMIP5 model performance in the Nile River headwaters regions. Int J Climatol 35:4262-4275

Brown ME, Funk Ch, Pedreros D, Korecha D, Lemma M, Rowland J, Williams E, Verdin J (2017) A climate trend analysis of Ethiopia: examining subseasonal climate impacts on crops and pasture conditions. Clim Change 142:169-182

Burn DH (1994) Hydrologic effects of climatic change in West Central. Can J Hydrol 160:53-70

Chapungu L, Nhamo L (2016) An assessment of the impact of climate change on plant species richness through an analysis of the normalized difference water index (NDWI) in Mutirikwi Sub-catchment, Zimbabwe South African. J Geomat 5(2):244-268

Conway D (2000) The climate and hydrology of the upper Blue Nile. Geogr J 166(1):49-62

Conway D (2005) From headwater tributaries to international river: observing and adapting to climate variability and change in the Nile basin. Glob Environ Change 15(2):99-114

Conway D, Schipper ELF (2011) Adaptation to climate in Africa: challenges and opportunities identified from Ethiopia. Glob Environ Change 21:227-237

Conway D, Mould C, Bewket W (2004) Over one century of rainfall and temperature observations in Addis Ababa, Ethiopia. Int J Climatol 24:77-91

Dale VH (1997) The relationship between land-use change and climate change. Ecol Appl 7(3):753-769

Deressa TT, Hassan RM (2009) Economic impact of climate on crop production in Ethiopia: evidence from cross-section measures. J Afr Econ 18(4):529-554

Elshamy ME, Seierstad IA, Sorteberg A (2009) Impacts of climate change on Blue Nile flows using bias-corrected GCM scenarios. Hydrol Earth Syst Sci 13:551-565

Foody GM (2003) Geographical weighting as a further refinement to regression modelling: an example focused on the NDVI-rainfall relationship. Remote Sens Environ 88:283-293

Foody GM (2004) Spatial nonstationary and scale-dependency in the relationship between species richness and environmental determinants for the sub-Saharan endemic avifauna. Glob Ecol Biogeogr 13:315-320 
Fotheringham AS, Brunsdon C, Charlton M (2002) Geographically weighted regression: the analysis of spatially varying relationships. Wiley, Chichester

Gebre H, Kindie T, Girma M, Belay K (2013) Trend and variability of rainfall in Tigray, Northern Ethiopia: analysis of meteorological data and farmers' perception. Acad J Agric Res 1(6):88-100

Gebremicael TG, Mohamed YA, Betrie GD, van der Zaag P, Teferi E (2013) Trend analysis of runoff and sediment fluxes in the upper Blue Nile basin: a combined analysis of statistical tests, physically-based models and land use maps. J Hydrol 482:57-68

Getahun YS, Shefine BG (2015) Analysis of climate variability (ENSO) and vegetation dynamics in Gojjam, Ethiopia. J Earth Sci Clim Change 6(10):320

Haile AT, Rientjes T (2015) Evaluation of regional climate model simulation of rainfall over the upper Blue Nile basin. Atmos Res 161-162:57-64

He Y, Lee E, Warner TA (2017) A time series of annual land use and land cover maps of China from 1982 to 2013 generated using AVHRR GIMM NDVI3g data. Remote Sens Environ. 199:201-217

IPCC (2007) Climate change 2007 the physical science basis. In: Solomon SD et al (eds) Contribution of working group I to the fourth assessment report of the intergovernmental panel on climate change. Cambridge University Press, Cambridge

IPCC (2013) Climate change 2013: the physical science basis. In: Stocker TF, Qin D, Plattner G-K, Tignor M, Allen SK, Boschung J, Nauels A, Xia Y, Bex V, Midgley PM (eds) Contribution of working group I to the fifth assessment report of the intergovernmental panel on climate change. Cambridge University Press, Cambridge, p 1535

Ji L, Peters AJ (2004) A spatial regression procedure for evaluating the relationship between AVHRR-NDVI and climate in the Northern Great Plains. Int J Remote Sens 25:297-311

Jiang Z, Huete AR, Chen J, Chen Y, Li J, Yan G, Zhang X (2006) Analysis of NDV and scaled difference vegetation index retrievals of vegetation fraction. Remote Sens Environ 101:366-376

Jury MR, Funk C (2012) Climatic trends over Ethiopia: regional signals and drivers. Int J Climatol 33:1924-1935

Keredin TS, Annisa M, Surendra B, Solomon A (2013) Long year comparative climate change trend analysis in terms of temperature, coastal Andhra Pradesh, India. Refer J Res Sci Technol 2(7):2277-1174

Kim U, Kaluarachchi JJ (2009) Climate change impacts on water resources in the upper Blue Nile River Basin Ethiopia. J Am Water Resour Assoc 45(6):1361-1378

Knutti R, Sedlacek J (2012) Robustness and uncertainties in the new CMIP5 climate model projections. Nat Clim Change. https://doi.org/10.1038/ NCLIMATE1716

Loranty M, Davydov SP, Kropp H, Alexander HD, Mack M, Natali SM, Zimov NS (2018) Vegetation indices do not capture forest cover variation in Upper Siberian Larch Forests. Remote Sens 10:1686

McMichael AJ, Woodruff RE, Hales S (2006) Climate change and human health: present and future risks. Lancet 367:859-869

Mekonnen DF, Disse M (2018) Analyzing the future climate change of upper Blue Nile River basin using statistical downscaling techniques. Hydrol Earth Syst Sci 22:2391-2408

Mekonnen DF, Duan Z, Rientjes T, Disse M (2018) Analysis of combined and isolated effects of land-use and land cover changes and climate change on the upper Blue Nile basin's streamflow. Hydrol Earth Syst Sci 22:6187-6207

Mellander P-E, Gebrehiwot SG, Gardenas Al, Bewket W, Bishop K (2013) Summer rains and dry seasons in the upper Blue Nile Basin: the predictability of half a century of past and future spatiotemporal patterns. PLOS ONE 8(7):e68461

Mengistu D, Bewket W, Lal R (2014) Recent spatiotemporal temperature and rainfall variability and trends over the upper Blue Nile Basin, Ethiopia. Int J Climatol 34:2278-2292

Ministry of Agriculture (MoA) (1998) Agro-ecological zones of Ethiopia. German Agency for Technical Cooperation (GTZ)

Musau J, Patil S, Sheffield J, Marshall M (2018) Vegetation dynamics and responses to climate anomalies in East Africa. Earth Syst Dyn Discuss. https://doi.org/10.5194/esd-2017-123

Perović V, Kadović R, Djurdjević V, Braunović S, Čakmak D, Mitrović M, Pavlović $P$ (2019) Effects of changes in climate and land use on soil erosion: a case study of the Vranjska Valley, Serbia. Reg Environ Change 19(4):1035-1046
Philip A, Augistine Y, Abindaw B (2014) Impact of climate variability on smallholder households and indigenous coping strategies in Bonga district. Int J Dev Res 4(3):693-699

Propastin P, Kappas M, Erasmi S (2008) Application of geographically weighted regression to investigate the impact of scale on prediction uncertainty by modelling relationship between vegetation and climate. Int J Spat Data Infrastruct Res 3:73-94

Regan PM, Kim H, Maiden E (2018) Climate change, adaptation, and agricultural output. Reg Environ Change 19(1):113-123

Rosell S (2011) Regional perspective on rainfall change and variability in the central highlands of Ethiopia 1978-2007. Appl Geogr 31:329-338

Samy A, Oliver C, Valeriano S, Negm A (2015) Variability of hydrological modeling of the Blue Nile. Int J Environ Chem Ecol Geol Geophys Eng 9(3):225-229

Schlenker W, Lobell DB (2010) Robust negative impacts of climate change on African agriculture. Environ Res Lett 5(1):014010

Segele ZT, Lamb PJ (2005) Characterization and variability of Kiremt rainy season over Ethiopia. Meteorol Atmos Phys 89:153-180

Seleshi Y, Zanke U (2004) Recent changes in rainfall and rainy days in Ethiopia. Int J Climatol 24(8):973-983

Sen PK (1968) Estimates of the regression coefficient based on Kendall's Tau. J Am Stat Assoc 63(324):1379-1389

Setegn SG, Rayner D, Melesse AM, Dargahi B, Srinivasan R (2011) Impact of climate change on the hydroclimatology of Lake Tana Basin Ethiopia. Water Resour Res 47:W04511

Tanzeeba S, Gan TY (2012) Potential impact of climate change on the water availability of South Saskatchewn River Basin. Clim Change 112:355-385

Teferi E, Uhlenbrook S, Bewket W (2015) Inter-annual and seasonal trends of vegetation condition in the upper Blue Nile (Abay) Basin: dual-scale time series analysis. Earth Syst Dyn 6:617-636

Tekleab S, Mohamed Y, Uhlenbrook S (2013) Hydro-climatic trends in the Abay/Upper Blue Nile basin, Ethiopia. Phys Chem Earth 61:32-42

Tena BA, Srinivasa RGVR, Yerramsetty A (2016) WEAP modeling of surface water resources allocation in Didessa Sub-Basin, West Ethiopia. Sustain Water Resour Manag 2:55-70

Tesemma ZK, Mohamed YA, Steenhuis TS (2010) Trends in rainfall and runoff in the Blue Nile Basin: 1964-2003. Hydrol Process 24:3747-3758

Tian F, Fensholt R, Verbesselt J, Grogan K, Horion S, Wang Y (2015) Evaluating temporal consistency of long-term global NDVI datasets for trend analysis. Remote Sens Environ 163:326-340

Tufa et al (2018) Enhancing national climate services (ENACTS) for development in Africa. Clim Dev 10(7):664-672

Usman U, Yelwa SA, Gulumbe SU, Danbaba A (2013) Modeling relationship between NDVI and climatic variables using geographically weighted regression. J Math Sci Appl 1(2):24-28

Vincent RT, Lemann GZ, Alemtsehay TS, Tibebu KN, Hans H (2018) Effects of climate change on water resources in the upper Blue Nile Basin of Ethiopia. Heliyon 4(2018):e00771

Viviroli et al (2011) Climate change and mountain water resources: overview and recommendations for research, management and policy. Hydrol Earth Syst Sci 15:471-504

Weldegerima TM, Zeleke TT, Birhanu BS, Zaitchik BF, Fetene ZA (2018) Analysis of rainfall trends and its relationship with SST signals in the Lake Tana Basin, Ethiopia. Adv Meteorol. https://doi. org/10.1155/2018/5869010

Worku G, Terefi E, Bantider A, Dile YT (2018) Observed changes in extremes of daily rainfall and temperature in Jemma sub-basin, upper Blue Nile Basin, Ethiopia. Theor Appl Climatol 135(3-4):839-854

Worqlul AW, Taddele YD, Ayana EK, Jeong J, Adem AA, Gerik Th (2018) Impact of climate change on streamflow hydrology in headwater catchments of the upper Blue Nile Basin, Ethiopia. Water 10:120

Yin H, Udelhoven Th, Fensholt R, Pflugmacher D, Hostert P (2012) How normalized difference vegetation index (NDVI) trends from advanced very highresolution radiometer (AVHRR) and Systeme Probatoire d'Observation de la Terre Vegetation (SPOT VGT) time series differ in agricultural areas: an inner Mongolian case study. Remote Sens 4:3364-3389

Yohannes $\mathrm{O}$ (2008) Water resources and inter-riparian relations in the Nile Basin: the search for an integrative discourse. Suny Press, Albany, p 270 
Zhao N, Yang Y, Zhou X (2010) Application of geographically weighted regression in estimating the effect of climate and site conditions on vegetation distribution in Haihe Catchment. China Plant Ecol 209:349-359

Zhao Z, Gao J, Wang Liu J, Li Sh (2015) Exploring spatially variable relationships between NDVI and climatic factors in a transition zone using geographically weighted egression. Theor Appl Climatol 120:507-519

\section{Publisher's Note}

Springer Nature remains neutral with regard to jurisdictional claims in published maps and institutional affiliations.
Submit your manuscript to a SpringerOpen ${ }^{\circ}$ journal and benefit from:

- Convenient online submission

- Rigorous peer review

- Open access: articles freely available online

- High visibility within the field

- Retaining the copyright to your article

Submit your next manuscript at $\boldsymbol{\nabla}$ springeropen.com 